\title{
1 Abrupt climate changes observed in late August over central \\ Japan between 1983 and 1984
}

19 Corresponding author:

Tomoshige Inoue

Tel: $+81-3-5841-4031$

Fax: +81-3-5841-8318

\author{
Tomoshige INOUE ${ }^{1,2}$ \\ and \\ Jun MATSUMOTO ${ }^{1 \#, 3}$ \\ 1: Department of Earth and Planetary Science, Graduate School of Science, \\ The University of Tokyo, Tokyo, Japan \\ 2: Research Fellow of the Japan Society for the Promotion of Science (JSPS) \\ 3: Institute of Observational Research for Global Change (IORGC), Japan Agency for \\ Marine-Earth Science and Technology (JAMSTEC), Yokosuka, Japan \\ \#: (Changed affiliation from 1 Aug., 2006) Department of Geography, \\ Graduate Schools of Urban Environmental Sciences, Tokyo Metropolitan University, \\ Hachioji, Japan
}

Department of Earth and Planetary Science, Graduate School of Science, The University of Tokyo, 7-3-1, Hongo, Bunkyo-ku, Tokyo 113-0033, Japan

E-mail: inoue@eps.s.u-tokyo.ac.jp 
Interdecadal climate changes occurring during the latter half of August (LA) in

4 central Japan are described, and the associated changes in rainfall, typhoon tracks and

5 circulation patterns over East Asia and the western North Pacific (WNP) regions are

6 investigated. Since 1984, rates of sunshine and temperature have increased, while

7 rainfall has decreased significantly during LA in central Japan. In contrast, rainfall

8 over the Southwest Islands of Japan, northern part of Taiwan, and in the south of the

9 middle and lower reaches of the Yangtze River in China has increased. Changes in the

10 positions and tracks of typhoon are responsible for these changes. Prior to 1983, many

11 typhoons approached the central-western part of Japan during LA, while after 1984,

12 most typhoons were deflected away from Japan and moved northwestward to Taiwan

13 and China. The North Pacific Subtropical High during LA extended more westward

14 after 1984, which affected the interdecadal changes in sunshine, temperature, rainfall and typhoon tracks, not only in central Japan, but also over East Asia and the WNP regions. 


\section{1. Introduction}

2 Recently, many kinds of decadal- to interdecadal-scale climate changes have been

3 detected in various regions of the world. One example of these changes is a sudden

4 interdecadal climate shift which occurred over the North Pacific in the late 1970s (e.g.,

$5 \quad$ Nitta and Yamada 1989; Trenberth 1990). This kind of sudden shift is called a climate

6 regime shift (Minobe 1997), which might be related to the Pacific Decadal Oscillation

7 (PDO) (e.g., Mantua et al. 1997). Although some hypotheses have been proposed, its

8 mechanism remains controversial. Associated with this shift, interdecadal changes

9 occurring in the late 1970s in the East Asian summer monsoon season have also been

10 pointed out by many researchers (e.g., Nitta and Hu 1996; Gong and Ho 2002).

11 A majority of the previously mentioned studies on interdecadal changes in the East

12 Asian summer monsoon season are based on June-August (JJA) mean data. However,

13 studies of climate changes over East Asia using these 3-month mean data seem to be

14 too simple to clarify the mechanism of these changes in detail. This is due to the fact

15 that there is a climatological intraseasonal oscillation in this region (e.g., Wang and

$16 \mathrm{Xu}$ 1997; LinHo and Wang 2002; Chen et al. 2004). Actually, there is an abrupt

17 wet/dry cycle over East Asia, due to a northward stepwise shift of the Baiu/Meiyu

18 frontal zone from May to July (e.g., Yoshino 1965) and a southward stepwise shift of

19 the Akisame (autumnal rain) frontal zone from August to October (e.g., Matsumoto

20 1988). In addition, typhoons often attack this area in a specific period, which also

21 contributes to the climatological seasonal variation of rainfall. Therefore, further

22 analyses using sub-seasonal to sub-monthly time-scale datasets are needed in order to

23 understand the precise mechanisms underlying interdecadal changes. Moreover,

24 Matsumoto (1992) revealed that some abrupt seasonal transitions of circulation

25 systems and convective activities occur almost simultaneously over broad regions of 
1 the whole monsoon area of Asia and northern Australia. Therefore, investigating the

2 interdecadal changes of seasonal marches is also important for improving

3 understanding of the Asian-Australian monsoon system.

4 To cite the studies from this viewpoint, Yamakawa (1988) studied seasonal and

5 secular variations in the prevailing pressure patterns over East Asia for the period

6 1941-85 and found a recent delay in the end of the Baiu season (early summer rainy

7 season in Japan) and a shortening of the midsummer dry season occurring since the

8 1970s. Sato and Takahashi (2001) took note of sunshine duration in midsummer (early

9 August) in Japan, and they showed that the sunshine duration in early August had a

10 decreasing trend for the period 1959-95, especially over the Sea of Japan side of

11 central Japan. They also suggested that a delay of the northward movement of the Baiu

12 frontal zone was likely to be associated with strengthening of the polar airmass (i.e.,

13 the Okhotsk high) around northern Japan. Inoue and Matsumoto (2003) investigated

14 the seasonal and secular changes of sunshine duration in Japan for the period 1951-

15 2000. They found that the end of the Baiu season has been delayed since 1980, which

16 is consistent with the previous studies described above. During the latter half of

17 August, on the other hand, a sunshine increase was observed in central-western Japan

18 after the early to mid-1980s. In other words, the long-term trends of sunshine duration

19 in this region are different, even within the same month (August). Since this region

20 has relatively rapid seasonal cycle, and is sandwiched between mid-latitude and

21 subtropical circulation regimes in summer, this result implies an existence of

22 interdecadal modulation of seasonal cycle there.

23 In the present study, we take note of the changes occurring during the latter half of

24 August (i.e., 16-31 August; denoted as "LA" hereafter) and further investigate the

25 interdecadal climate changes observed in the 1980s during LA in central Japan. Then 
1 we examine the interdecadal changes in rainfall patterns over East Asia during LA.

2 Typhoons and tropical cyclones bring much rain and extraordinarily strong wind,

3 and sometimes cause severe disasters over East Asia. Ho et al. (2004) and Wu et al.

4 (2005a) documented interdecadal variations in typhoon activity in the western North

5 Pacific (WNP) region and their influence over East Asia during the typhoon season

6 (June-September or June-October). Typhoons themselves are also important

7 phenomena for seasonal cycles over East Asia, and August is the month in which

8 tropical cyclone and typhoon activity over the WNP is the strongest of the year (e.g.,

9 Chan 2005). Yoshino and Kai (1977) and Yamakawa (1988) noticed that the "typhoon

10 type" pressure pattern in the vicinity of Japan appeared most frequently during mid- to

11 late August. Therefore, it is possible that statistics of typhoon activity during LA have

12 also changed since the early 1980 s. We, thus, also analyze the interdecadal changes of

13 typhoon tracks and circulation patterns over East Asia and the WNP regions.

14 Section 2 describes data utilized in the present study. In section 3, we analyze 15 observational station data from Japan and clarify the changes observed during LA.

16 Section 4 examines the changes in rainfall patterns over East Asia, and section 5

17 describes the changes in typhoon tracks over the WNP region. Comparisons of 18 atmospheric circulation in the mid-troposphere are attempted in section 6. Major 19 conclusions and discussions are described in the last section. 


\section{2. Data}

2 Daily station data for sunshine duration and rainfall in Japan were obtained from the

3 surface daily product (SDP) data CD-ROMs and the annual report CD-ROMs, 4 published or released by the Japan Meteorological Agency (JMA). We used 115 5 observational stations in Japan, where continuous observations data are available for 6 the period 1961-2000 without any location movement (Fig. 1).

$7 \quad$ During the late 1980 s, the JMA replaced the Jordan sunshine recorders (which use a 8 closed can with a pinhole on one side to let sunlight onto light-sensitive paper) with 9 rotating mirror sunshine recorders (which use a specially designed rotating mirror that 10 reflects the sun's direct component onto a spectrally flat pyroelectric sensor).

11 Referring to Katsuyama (1987), the observed values before the replacement were 12 calibrated as

where $S_{J}$ is the observed value of daily sunshine duration obtained by the Jordan sunshine recorder before the replacement, and $S_{R}$ is a calibrated value corresponding to the rotating mirror sunshine recorder. This relationship was determined based on the results of simultaneous observational comparisons between the two sunshine recorders.

19 We calculated rates of sunshine (values of sunshine duration divided by possible 20 duration of sunshine) and used that instead of sunshine duration because of the 21 latitudinal difference of possible duration of sunshine (PDS). PDS [hr day ${ }^{-1}$ is 22 calculated as

$$
\operatorname{PDS}=\frac{24}{\pi} \arccos (-\tan \theta \tan \delta)
$$

where $\theta$ [degree] is the latitude of the station, and $\delta$ [degree] is the solar declination 
1 parameter determined by date of the day.

2 We also used daily rainfall data from 123 stations in China, compiled by the China

3 Meteorological Administration, 18 stations in Taiwan, compiled by the Central

4 Weather Bureau, and 15 stations in South Korea, compiled by the Korea

5 Meteorological Administration (Fig. 1).

6 For typhoon statistics, we utilized "RSMC (Regional Specialized Meteorological

7 Center) best track data" over the WNP region that was obtained from the web site of

8 the RSMC Tokyo-Typhoon Center (http://www.jma.go.jp/jma/jma-eng/jma-

9 center/rsmc-hp-pub-eg/RSMC_HP.htm). For the present study, "typhoons" were

10 defined as tropical cyclones of which maximum sustained wind speeds are greater than

$1117 \mathrm{~m} \mathrm{~s}^{-1}$, and the 4-time daily data $(03,09,15$, and 21 Japan Standard Time) were used.

12 As for upper-air wind data, the 40-year Reanalysis (ERA-40) daily data (Uppala et

13 al. 2005) from the European Centre for Medium-Range Weather Forecasts (ECMWF)

14 were used. These data are available from the data server of the ECMWF web site

15 (http://data.ecmwf.int/data/d/era40_daily/), with grid intervals of $2.5^{\circ}$ (latitude) $\times 2.5^{\circ}$

16 (longitude). The ERA-40 seems to be better than another long-term reanalysis dataset,

17 the National Centers for Environmental Prediction-National Center for Atmospheric

18 Research (NCEP-NCAR) reanalysis, in investigations of interdecadal climate

19 variations over East Asia (Inoue and Matsumoto 2004; Wu et al. 2005b). 
1 3. Interdecadal changes detected from observational station data in

2 Japan

3 As described in section 1, sunshine duration during LA has increased over central-

4 western Japan since the early to mid-1980s, which is opposite tendency (sunshine

5 decrease since the 1980s) to that in late July and the former half of August over there

6 (Inoue and Matsumoto 2003). To highlight the change during LA, we sought a "core

7 region" of this change, where the changes were most clearly recognized. After

8 examining interdecadal variations of sunshine during LA at each station, 24 stations

9 located on the Pacific Ocean side of central Japan were selected. These stations are

10 plotted as open circles in Fig. 1. Figure 2a shows the interannual variation in rates of

11 sunshine during LA, averaged over the 24 stations. As already indicated by Inoue and

12 Matsumoto (2003), the rates of sunshine abruptly increased in the early to mid-1980s.

13 This increase appears to be a discontinuous change in the early 1980s, rather than a

14 linear trend. To determine the discontinuous year of this shift, the Lepage test (Lepage

15 1971) was conducted. The Lepage test is a non-parametric test that investigates

16 significant differences between two samples. Yonetani $(1992,1993)$ showed that this

17 statistical test is very useful for detecting discontinuous climate changes. The result of

18 the Lepage test (sample numbers $\mathrm{n}_{1}=\mathrm{n}_{2}=12$ ) is shown in Fig. 2b. The Lepage

19 statistic, HK, which indicates a degree of discontinuity, has a peak in $1983 / 84$ that is

20 significant at a 95\% confidence level. We also checked the results of the Lepage test

21 when the sample numbers $\left(\mathrm{n}_{1}\right.$ and $\left.\mathrm{n}_{2}\right)$ changed from 10 to 18 , and we confirmed that

22 the peak in 1983/84 was unchanged (figures not shown). Thus, we divided the

23 analyzed years into two periods: 1961-83 and 1984-2000. Hereafter, we mainly focus

24 on the difference between the two periods during LA.

25 Figure 3 compares seasonal variations of rates of sunshine during the warm season, 
1 averaged in 1961-83 and 1984-2000 over the 24 stations. Climatologically, after a

2 little-sunshine season during mid-June to mid-July (the Baiu rainy season in central-

3 western Japan), a dry and much-sunshine season (midsummer) begins in late July

4 (Maejima 1967; Inoue and Matsumoto 2003). In 1961-83, the much-sunshine season

5 had its highest peak in early August, but it did not last long. Sunshine rather abruptly

6 decreased after LA and decreased again toward another little-sunshine season during

7 mid-September to early October (the Akisame rainy season or autumnal rains in

8 central-western Japan). The most obvious difference between 1961-83 and 1984-2000

9 was a sunshine increase during LA. The peak of sunshine shifts to LA, and

10 midsummer (much-sunshine season) has recently been prolonged to as late as early

11 September.

12 Figure 4 shows the difference in rates of sunshine (1984-2000 minus 1961-83) in

13 Japan during LA. Rates of sunshine have increased at a large number of stations in

14 central Japan, and significantly-increased stations at a $95 \%$ confidence level

15 according to the Student's t-test are distributed over the Pacific Ocean side of central

16 Japan. In contrast sunshine has decreased at some stations in Hokkaido, southern and

17 western Kyushu, and the Southwest Islands. This geographical pattern is similar to the

18 opposite situation of the recent sunshine changes in early August in Japan (Sato and

19 Takahashi 2001). This distribution implies an intensification of the influence of the

20 North Pacific Subtropical High (NPSH) over this region during LA, which will be

21 discussed in section 6.

22 The interdecadal changes during LA described above were observed not only in

23 sunshine but also in temperature and rainfall. Figure 5a shows seasonal variations of

24 pentad mean temperature as in Fig. 3. Temperature has increased through the warm

25 season, in particular after LA. We checked the Student's t-test for the eight 15(16)-day 
1 periods from June to September (1-15 June, 16-30 June, ..., and 16-30 September).

2 Although temperature has increased in all periods, those before 1-15 August are not

3 significant at a 95\% level. The periods between 16-31 August and 16-30 September

4 pass a $95 \%$ confidence level, and only LA passes a $99 \%$ confidence level. Figure 5 b

5 compares the seasonal variations in rainfall averaged for the same stations. During LA,

6 the rainfall decreased obviously after 1984. The rainfall in 1984-2000 during LA (4.2

$\left.7 \mathrm{~mm} \mathrm{day}^{-1}\right)$ was approximately half of that in 1961-83 (8.0 $\left.\mathrm{mm} \mathrm{day}^{-1}\right)$, and this decrease

8 is significant at a $99 \%$ confidence level according to the Student's t-test. Both the

9 temperature increase and the rainfall decrease occurred abruptly in 1983/84 (Figs. 5c

10 and $d$ ), and the discontinuity is confirmed by the Lepage test at a $95 \%$ confidence

11 level (figures not shown for both time series).

12

13

14

15

16

17

18

19

20

21

22

23

24

25 


\section{4. Interdecadal changes of rainfall over East Asia during LA}

2 Figure 6 shows a spatial pattern of the 1983/84 change in rainfall during LA over

3 East Asia. Stations where rainfall decreased are concentrated on the Pacific Ocean side

4 of central Japan. In contrast, rainfall over the southern portion of the Southwest

5 Islands of Japan, northern part of Taiwan and southern part of China (the middle and

6 lower reaches of the Yangtze River Valley and to the south) increased. In particular,

7 stations with significant rainfall increases were found to be located in 1) the

8 southwestern-most part of Japan (the Sakishima Islands) and northern Taiwan (24․

$926^{\circ} \mathrm{N}, 120^{\circ}-126^{\circ} \mathrm{E}$; denoted as "SI-NT"), and 2) the middle and lower reaches of the

10 Yangtze River Valley $\left(27^{\circ}-32^{\circ} \mathrm{N}, 110^{\circ}-122.5^{\circ} \mathrm{E}\right.$; denoted as "YRV”). Rainfall has also

11 increased in Korea, though the increase is not significant.

12 Figure 7 compares the seasonal variations in rainfall, averaged over the above two 13 regions between 1961-83 and 1984-2000. In 1961-83, over the SI-NT region (Fig. 7a), 14 rainfall during LA showed a temporal minimum, in particular at the end of this time 15 period. In 1984-2000, on the other hand, LA became one of the highest rainfall periods 16 in the warm season. The increase during LA is significant at a $99 \%$ confidence level, 17 according to the Student's t-test. Over the YRV region (Fig. 7b), there is a primary 18 peak during June to early July (the Meiyu season). After the end of the Meiyu season, 19 a relatively dry season starts in mid-July. Another rainfall peak, although not very 20 striking, exists in August over this region. This peak seems to shift from mid- to late 21 August. Therefore, rainfall at several stations within the YRV region has increased 22 significantly during LA. The increase during LA is significant at a $90 \%$ confidence 23 level, according to the Student's t-test. 


\section{5. Changes of typhoon tracks over the WNP region during LA}

2 In the previous section, we showed the interdecadal change of rainfall over East

3 Asia. Since typhoons bring much rain in the warm season over East Asia, the 1983/84

4 changes in typhoon activity over the WNP region during LA are examined in this

5 section. Figures $8 \mathrm{a}$ and $8 \mathrm{~b}$ show genesis locations and tracks of typhoons over the

6 WNP region during LA in 1961-83 and 1984-2000, respectively. In 1961-83 (Fig. 8a),

7 typhoon tracks were concentrated in the vicinity of the Southwest Islands of Japan and

8 the Pacific Ocean side of central-western Japan. A number of typhoons occurred over

9 the tropical WNP, moved northward along approximately $130^{\circ} \mathrm{E}$, and then curved east-

10 northeastward along the southern coast of central-western Japan. In 1984-2000 (Fig.

$118 \mathrm{~b}$ ), on the other hand, there were many typhoons which moved northwestward in the

12 vicinity of Taiwan and over the northern part of the South China Sea (SCS). Typhoons

13 in the vicinity of central-western Japan have obviously decreased.

14 To quantitatively examine the spatial variations in typhoon positions, the typhoon 15 passage frequency within each $5^{\circ} \times 5^{\circ}$ grid box from the original 6 -hourly datasets was

16 calculated. Since probability density functions of the typhoon passage frequency

17 within each grid are quite different from the normal distribution, significance levels

18 were estimated from the Monte Carlo simulations, rather than the Student's t-test, by

19 using 10,000 randomized time series. The details are as follows: Firstly 9,999

20 randomly sorted 40-year time series of the typhoon passage frequency values are

21 prepared, and then averages of the former 23-year values minus those of the latter 17-

22 year values are calculated. From the rank of the original difference value among

2310,000 samples, the significance level is estimated. Figure $8 \mathrm{c}$ shows the difference in

24 the typhoon passage frequency (1984-2000 minus 1961-83) during LA. The typhoon

25 passage frequency has significantly decreased over central-western Japan and its 
1 neighboring ocean to the south $\left(25^{\circ}-35^{\circ} \mathrm{N}, 125^{\circ}-140^{\circ} \mathrm{E}\right.$; denoted as "CWJ"). On the

2 other hand, the frequency has increased over the northern SCS and in the vicinity of

3 Taiwan and the Philippines $\left(15^{\circ}-25^{\circ} \mathrm{N}, 105^{\circ}-130^{\circ} \mathrm{E}\right.$; denoted as "SCS-TP").

4 Figure 9 shows the seasonal variations in typhoon passage frequency in 1961-83 and

5 1984-2000 over the two box areas. In the CWJ area (Fig. 9a), a peak during mid- to

6 late August in 1961-83 is clear. In 1984-2000, on the other hand, the peak disappears,

7 and the typhoon passage frequency during LA decreases by half. This decrease during

8 LA is significant at $95 \%$ level estimated from the Monte Carlo simulation. In recent

9 years, a peak before LA (late July to early August) has become obvious. Over the

10 SCS-TP area (Fig. 9b), the most active typhoon season during the period of 1961-83

11 existed during September. However, the beginning of this season has become earlier in

12 recent years. In 1984-2000, the typhoon passage frequency during LA increased twice

13 as much as that of 1961-83 (significant at a 99\% confidence level estimated from the

14 Monte Carlo simulation), in sharp contrast to the situations in the CWJ area.

15 These changes in the typhoon passage frequency are closely related to the 16 interdecadal changes in rainfall in central Japan. Figure 10 shows seasonal variations 17 in the accumulated rainfall, averaged at the 24 stations (same as those of Figs. 2, 3 and 18 5) in central Japan, when typhoons existed within the CWJ area. A drastic decrease in 19 the typhoon-influenced rainfall is recognized during LA. This decrease is significant at a $99 \%$ confidence level. This result indicates that the interdecadal decrease in

21 rainfall over central Japan during this season is strongly influenced by the interdecadal 22 change in typhoon activity over the WNP. 


\section{6. Changes of upper-air circulation}

2 Typhoon tracks are essentially controlled by large-scale atmospheric circulation

3 patterns in the mid-troposphere. Therefore, the changes in typhoon tracks shown in the

4 previous section may be related to large-scale circulation changes over the WNP.

5 Steering flow which influences tropical cyclone motion has investigated by many

6 researchers (e.g., George and Gray 1976; Chan and Gray 1982). Holland (1984)

$7 \quad$ suggested that the pressure-weighted layer mean flow from 850 to $300 \mathrm{hPa}$ appeared to

8 correlate reasonably well with tropical cyclone movement. Here, we calculated and

9 compared this pressure-weighted flow in 1961-83 and 1984-2000 during LA (Figure

10 11). In 1961-83, a westward extension of the NPSH was not strong, and southerly

11 winds prevailed along the western periphery of the NPSH to the south of Japan. In

12 1984-2000, in contrast, the westward extension of the NPSH was stronger, and the

13 ridge line near Japan $\left(130^{\circ}-140^{\circ} \mathrm{E}\right)$ was located slightly more northward than it had

14 been prior to the early 1980 s (i.e., south of $30^{\circ} \mathrm{N}$ in $1961-83$; north of $30^{\circ} \mathrm{N}$ in $1984-$

15 2000). The difference in wind vector (1984-2000 minus 1961-83, figure not shown)

16 indicates that the wind change in the south of Japan, which indicates stronger

17 anticyclonic circulation in the vicinity of central Japan, is significant at a $95 \%$

18 confidence level.

19 To compare the seasonal retreat of the western peripheries of the NPSH, time20 longitude cross sections of the meridional wind component of the pressure-weighted $21 \quad(300-850 \mathrm{hPa})$ steering flow along $30^{\circ} \mathrm{N}$ from July to September in 1961-83 and 1984222000 were compared in Figure 12. In 1961-83, the southerly component was the 23 strongest over eastern China (the middle and lower reaches of the Yangtze River 24 Valley) and/or the western part of the East China Sea $\left(115^{\circ}-125^{\circ} \mathrm{E}\right)$ until early August.

25 Then, a sudden eastward shift of the southerly wind maximum occurred in mid-August 
1 and stagnated in the south of Japan $\left(135^{\circ}-140^{\circ}\right.$ E) until September. In 1984-2000, on

2 the other hand, the first retreat from eastern China and/or the western part of the East

3 China Sea occurred as early as late July to early August, but the maximum of the

4 southerly wind component (western periphery of the NPSH) remained in the vicinity

5 of Kyushu (around $130^{\circ} \mathrm{E}$ ) until the end of August. The southerly wind component to

6 the south of Japan $\left(135^{\circ}-140^{\circ} \mathrm{E}\right)$ was not strong, even in late August, and the second

7 eastward movement occurred in early to mid-September.

8 These results imply that the changes in typhoon tracks (and possibly the changes in

9 rainfall, sunshine and temperature over East Asia) during LA are attributable to the

10 recent stagnant tendency of the seasonal eastward retreat of the NPSH. During LA

11 prior to 1983 , the western periphery of the NPSH retreated eastward earlier. Thus, the

12 seasonal changes in sunshine decrease and rainfall increase were brought about

13 directly. In addition, it gave favorable conditions for many typhoons to approach

14 central-western Japan. Therefore, rainfall supplied from the typhoons was also

15 abundant over this region. After 1984, in contrast, the western periphery of the NPSH

16 was stagnant over the East China Sea and in the vicinity of Kyushu until the end of

17 August. The conditions of much sunshine and little rainfall thus continued even into

18 late August. As most typhoons are deflected northwestward from the WNP toward

19 Taiwan and the southern part of China, the midsummer dry season in central-western

20 Japan now lasts until early September, and the rainfall in the SI-NT and YRV regions

21 has increased during LA. 


\section{7. Conclusions and discussions}

2 We clarified the interdecadal climate changes occurring during the latter half of

3 August (LA) in central Japan, and investigated their associated changes in rainfall,

4 typhoon tracks and circulation patterns over East Asia and the western North Pacific

5 (WMP) regions. Since 1984, rates of sunshine and temperature have increased, while

6 rainfall has decreased significantly in central Japan during LA. At the same time,

7 rainfall over the Southwest Islands of Japan, northern part of Taiwan and the middle

8 and lower reaches of the Yangtze River Valley has increased. These changes are

9 attributable to the clear changes in the positions and tracks of typhoon in the WNP.

10 Prior to 1983, many typhoons approached the central-western part of Japan during LA.

11 After 1984, on the other hand, most typhoons were deflected away from Japan and

12 moved northwestward to Taiwan and China. Changes in the circulation patterns in the

13 mid-troposphere over the WNP region indicate that, over the oceanic area in the south

14 of Japan, the North Pacific Subtropical High during LA has extended more westward

15 since 1984. This is related to the delay of the eastward retreat of the Subtropical High

16 during LA in recent years. These changes in the circulation patterns affect the

17 interdecadal changes in sunshine, temperature, rainfall and typhoon tracks, not only in

18 central Japan, but also over East Asia and the WNP regions.

19 As mentioned in section 3, the changes in LA discovered in the present study are opposite to those that occur in late July and early August, a fact pointed out by Sato

21 and Takahashi (2001) and Inoue and Matsumoto (2003). Sato and Takahashi (2001)

22 suggested that long-term changes, such as sunshine decrease in early August, were

23 mainly due to the recent slower northward movement of the Baiu frontal zone in the

24 vicinity of Japan as well as the strengthening of the polar airmass over northern Japan

25 (i.e., the Okhotsk High). However, the influences of the Baiu (Meiyu) frontal zone and 
1 the Okhotsk High on Japan are no longer strong during LA, because the thermal

2 contrast in the vicinity of the Sea of Okhotsk (i.e., warmness of the Siberian landmass

3 and coolness of the North Pacific Ocean), which is connected to the strength of the

4 Okhotsk High (Nakamura and Fukamachi 2004; Tachibana et al. 2004), disappears

5 until LA (figure not shown). Therefore, some other mechanisms, which make the

6 opposite impact to those in late July and early August, may bring the interdecadal

7 changes during LA.

8 The changes of typhoon activity and the NPSH imply that the interdecadal changes

9 observed in central Japan seem to be reflection of interdecadal changes of seasonal

10 marches over East Asian and WNP monsoon region, rather than local phenomena. It is

11 a next step to clarify the reason for the changes in the NPSH. From Fig. 9b, typhoon

12 passage frequency has changed over the tropical WNP region on an intraseasonal

13 timescale. Since the intraseasonal variation of monsoon activity over the WNP is

14 seasonally phase-locked (Nakazawa 1992), it is implied that the phase-locked tropical

15 intraseasonal variation has changed interdecadally, and may be related to the recent

16 stronger NPSH in the vicinity of Japan (Fig. 11) through the Rossby wave response,

17 known as the PJ pattern (Nitta 1987). Meanwhile, LA is a transitional season from a

18 subtropical regime to a mid-latitude regime over central and western Japan. It is

19 possible that the relationship between this steady seasonal transition in mid-latitude

20 and the phase-locked intraseasonal variation over the tropical WNP region has

21 changed on the interdecadal timescale. However, interdecadal climate jumps in the

22 early 1980 s are not well-known over other regions of the world. Therefore, whether a

23 relationship with other mechanisms of climate changes, such as PDO or global

24 warming, exists or not is an important question to be solved. To clarify the whole

25 mechanism, further investigations are needed in the future. 
2 We appreciate valuable comments and suggestions from the two anonymous

3 reviewers. We are also thankful to Mr. Hideaki Shoji of the University of Tokyo for

4 our use of the typhoon data file which he obtained and processed, Dr. Rena Nagata of

5 Tokyo Metropolitan University for access to the daily rainfall data in Taiwan and

6 Korea, and Dr. Kiyotoshi Takahashi of the Meteorological Research Institute, Dr.

7 Shinji Nakagawa of the JMA, and Dr. Yasushi Agata of the University of Tokyo for

8 helping the provision of the daily rainfall data in China.

9 The Grid Analysis and Display System (GrADS), distributed from the Center for 10 Ocean-Land-Atmosphere Studies (COLA), and the Generic Mapping Tools (GMT), distributed from the School of Ocean and Earth Science and Technology (SOEST) at the University of Hawaii, were utilized for the drawing part of the figures.

Part of this study is financially supported by the Grant-in-Aid for JSPS Fellows from the Japanese Ministry of Education, Culture, Sports, Science and Technology (16-11316) and by CREST (Core Research for Evolutional Science and Technology) of JST (Japan Science and Technology Agency). 
2 Chan, J. C. L., 2005: Interannual and interdecadal variations of tropical cyclone 3 activity over the western North Pacific. Meteor. Atmos. Phys., 89, 143-152. , and W. M. Gray, 1982: Tropical cyclone movement and surrounding flow

$5 \quad$ relationships. Mon. Wea. Rev., 110, 1354-1374.

6 Chen, T.-C., S.-Y. Wang, W.-R. Huang, and M.-C. Yen, 2004: Variation of the East

Asian summer monsoon rainfall. J. Climate, 17, 744-762.

George, J. E., and W. M. Gray, 1976: Tropical cyclone motion and surrounding parameter relationships. J. Appl. Meteor., 15, 1252-1264.

Gong, D.-Y., and C.-H. Ho, 2002: Shift in the summer rainfall over the Yangtze River valley in the late 1970s. Geophys. Res. Lett., 29, 1436, doi:10.1029/2001GL014523.

Ho, C.-H., J.-J. Baik, J.-H. Kim, and D.-Y. Gong, 2004: Interdecadal changes in summertime typhoon tracks. J. Climate, 17, 1767-1776.

Holland, G. J., 1984: Tropical cyclone motion: A comparison of theory and observation. J. Atmos. Sci., 41, 68-75.

Inoue, T., and J. Matsumoto, 2003: Seasonal and secular variations of sunshine duration and natural seasons in Japan. Int. J. Climatol., 23, 1219-1234. , and ______ 2004: A comparison of summer sea level pressure over East Eurasia between NCEP-NCAR reanalysis and ERA-40 for the period 1960-99. J. Meteor. Soc. Japan, 82, 951-958.

Katsuyama, M., 1987: On comparison between rotating mirror sunshine recorders and Jordan sunshine recorders. Weather Service Bulletin, 54, 169-183 (in Japanese).

Lepage, Y., 1971: A combination of Wilcoxon's and Ansari-Bradley's statistics. Biometrika, 58, 213-217. 
1 LinHo, and B. Wang, 2002: The time-space structure of the Asian-Pacific summer

2 monsoon: A fast annual cycle view. J. Climate, 15, 2001-2019.

3 Maejima I., 1967: Natural seasons and weather singularities in Japan. Geographical

4 Reports of Tokyo Metropolitan University, 2, 77-103.

5 Mantua, N. J., S. R. Hare, Y., Zhang, J. M. Wallace, and R. C. Francis, 1997: A Pacific

6 interdecadal climate oscillation with impacts on salmon production. Bull. Amer.

$7 \quad$ Meteor. Soc., 78, 1069-1079.

8 Matsumoto, J., 1988: Large-scale features associated with the frontal zone over East

9 Asia from late summer to autumn. J. Meteor. Soc. Japan, 66, 565-579.

10 1992: The seasonal changes in Asian and Australian monsoon regions. $J$. Meteor. Soc. Japan, 70, 257-273.

Minobe, S., 1997: A 50-70 year climatic oscillation over the North Pacific and North America. Geophys. Res. Lett., 24, 683-686.

14 Nakamura, H., and T. Fukamachi, 2004: Evolution and dynamics of summertime 15 blocking over the Far East and the associated surface Okhotsk high. Quart. J. Roy. 16 Meteor. Soc., 130, 1213-1233.

Nakazawa, T., 1992: Seasonal phase lock of intraseasonal variation during the Asian 18 summer monsoon. J. Meteor. Soc. Japan, 70, 597-611.

19 Nitta, T., 1987: Convective activities in the tropical western Pacific and their impact 20 on the Northern Hemisphere summer circulation. J. Meteor. Soc. Japan, 65, 373-390. , and S. Yamada, 1989: Recent warming of tropical sea surface temperature , and Z.-Z. Hu, 1996: Summer climate variability in China and its association with $500 \mathrm{hPa}$ height and tropical convection. J. Meteor. Soc. Japan, 74, 425-445. 
1 Sato, N., and M. Takahashi, 2001: Long-term variations of the Baiu frontal zone and

2 midsummer weather in Japan. J. Meteor. Soc. Japan, 79, 759-770.

3 Tachibana, Y., T. Iwamoto, M. Ogi, and Y. Watanabe, 2004: Abnormal meridional 4 temperature gradient and its relation to the Okhotsk high. J. Meteor. Soc. Japan, 82, $5 \quad 1399-1415$.

6 Trenberth K. E., 1990: Recent observed interdecadal climate changes in the Northern $7 \quad$ Hemisphere. Bull. Amer. Meteor. Soc., 71, 988-993.

8 Uppala, S. M., and Coauthors, 2005: The ERA-40 re-analysis. Quart. J. Roy. Meteor. $9 \quad$ Soc., 131, 2961-3012.

10 Wang, B., and X. Xu, 1997: Northern Hemisphere summer monsoon singularities and 11 climatological intraseasonal oscillation. J. Climate, 10, 1071-1085.

12 Wu, L., B. Wang, and S. Geng, 2005a: Growing typhoon influence on east Asia. 13 Geophys. Res. Lett., 32, L18703, doi:10.1029/2005GL022937.

14 Wu, R., J. L. Kinter III, and B. P. Kirtman, 2005b: Discrepancy of interdecadal 15 changes in the Asian region among the NCEP-NCAR reanalysis, objective analyses, 16 and observations. J. Climate, 18, 3048-3067.

17 Yamakawa, S., 1988: Climatic variations in recent years from the viewpoint of the 18 seasonal transition of prevailing pressure pattern over East Asia. Geogr. Rev. Japan, 19 61A, 381-403 (in Japanese with English abstract).

20 Yonetani, T., 1992: Discontinuous changes of precipitation in Japan after 1900 21 detected by the Lepage test. J. Meteor. Soc. Japan, 70, 95-104. 1993: Detection of long term trend, cyclic variation and step-like change by

23 the Lepage test. J. Meteor. Soc. Japan, 71, 415-418.

24 Yoshino, M. M., 1965: Four stages of the rainy season in early summer over East Asia 25 (Part I). J. Meteor. Soc. Japan, 43, 231-245. 

, and K. Kai, 1977: The divisions and characteristics of the natural seasons of

2 Japan. Geogr. Rev. Japan, 50, 635-651 (in Japanese with English abstract). 
FIG. 1. Observational stations used in the present study. Open circles: the 24 stations on the Pacific Ocean side of central Japan, where the interdecadal sunshine increase is very clear (see text in section 3). Triangles: other stations in Japan, from which sunshine and rainfall data were taken for the present study. Closed circles: stations in China, Taiwan and Korea, from which only rainfall data were taken.

FIG. 2. (a) Interannual variation in the rates of sunshine, averaged over the 24 stations (open circles in Fig. 1), during 16-31 August (thin line) and its 7-year binomial running mean (thick line). (b) Time series of the Lepage statistic (HK), when the sampling numbers of the two groups are $12(\mathrm{yr})$. The $95 \%$ confidence level of this test is indicated by a broken line.

FIG. 3. Seasonal variations in the rates of sunshine (\%), averaged over the 24 stations in 1961-83 (broken line) and 1984-2000 (solid line). Daily values are compiled into pentad (5-day) mean ones, and the period of 16-31 August (LA) is shaded.

FIG. 4. Difference in the rates of sunshine (\%, 1984-2000 minus 1961-83) in Japan during 16-31 August (LA). Contour intervals are 2\%. Light shading indicates a region of more than $8 \%$ increase in the rates of sunshine, and heavy shading indicates a region of decrease in sunshine. Open circles indicate the stations (a closed square indicates the station) where the increase (decrease) is significant at a $95 \%$ confidence level, according to the Student's t-test. 
FIG. 5. (a) As in Fig. 3, except pentad-mean temperature $\left({ }^{\circ} \mathrm{C}\right)$. (b) As in Fig. 3, except rainfall (mm day $\left.{ }^{-1}\right)$. (c) As in Fig. 2a, except pentad-mean temperature $\left({ }^{\circ} \mathrm{C}\right) .(\mathrm{d})$ As in Fig. 2a, except rainfall $\left(\mathrm{mm} \mathrm{day}^{-1}\right)$.

FIG. 6. Spatial pattern of the interdecadal change in rainfall $\left[100 \times\left(\mathrm{R}_{1984-2000}-\right.\right.$ $\left.\mathrm{R}_{1961-83}\right) / \mathrm{R}_{1961-83}(\%)$, where $\mathrm{R}_{1961-83}\left(\mathrm{R}_{1984-2000}\right)$ is a rainfall amount during $\mathrm{LA}$ averaged in 1961-83 (1984-2000)] over East Asia. Contour intervals are 25\%. Heavy (light) shading indicates a region of more than $25 \%$ rainfall increase (decrease). Closed squares (open circles) are the stations where the increase (decrease) is significant at a 95\% confidence level, and closed triangles (inverse open triangles) are the stations where the increase (decrease) is significant at a 90-95\% level, according to the Student's t-test. Two boxes show regions where seasonal variations in rainfall are shown in Fig. 7.

FIG. 7. (a) As in Fig. 5b, except in the SI-NT region $\left(24^{\circ}-26^{\circ} \mathrm{N}, 120^{\circ}-126^{\circ} \mathrm{E}\right)$ and (b) in the YRV region $\left(27^{\circ}-32^{\circ} \mathrm{N}, 110^{\circ}-122.5^{\circ} \mathrm{E}\right)$.

FIG. 8. Genesis locations (open circles) and tracks (dots with lines) of all typhoons that existed during 16-31 August (LA) over the WNP region in (a) 1961-83 and (b) 1984-2000, and (c) the difference in the typhoon passage frequency (\%) within each $5^{\circ} \times 5^{\circ}$ grid box (1984-2000 minus 1961-83) during LA. For (c), contour intervals are $1 \%$, and heavy (light) shading indicates a significant increase (decrease) at a $95 \%$ confidence level, estimated from the Monte Carlo simulations (10,000 resampling trials). Two boxes are regions where seasonal variations in typhoon passage frequency are shown in Fig. 9. 
FIG. 9. As in Fig. 3, except the typhoon passage frequency (\%) over the (a) CWJ and (b) SCS-TP areas.

FIG. 10. As in Fig. 3, except the accumulated rainfall $\left(\mathrm{mm} \mathrm{day}^{-1}\right)$ when typhoons existed within the CWJ area.

FIG. 11. Pressure-weighted (300-850 hPa) horizontal wind circulation during the period of 16-31 August (LA) in (a) 1961-83 and (b) 1984-2000.

FIG. 12. Time-longitude sections of the meridional wind component of the pressureweighted (300-850 hPa) flow along $30^{\circ} \mathrm{N}$ from July to September in (a) 1961-83 and (b) 1984-2000 (smoothed by a 25-day unweighted running mean). Contour intervals are $0.5 \mathrm{~m} \mathrm{~s}^{-1}$, and areas where the southerly wind component is stronger than $2 \mathrm{~m} \mathrm{~s}^{-1}$ are shaded. Dashed lines indicate the beginning and the end of LA. 


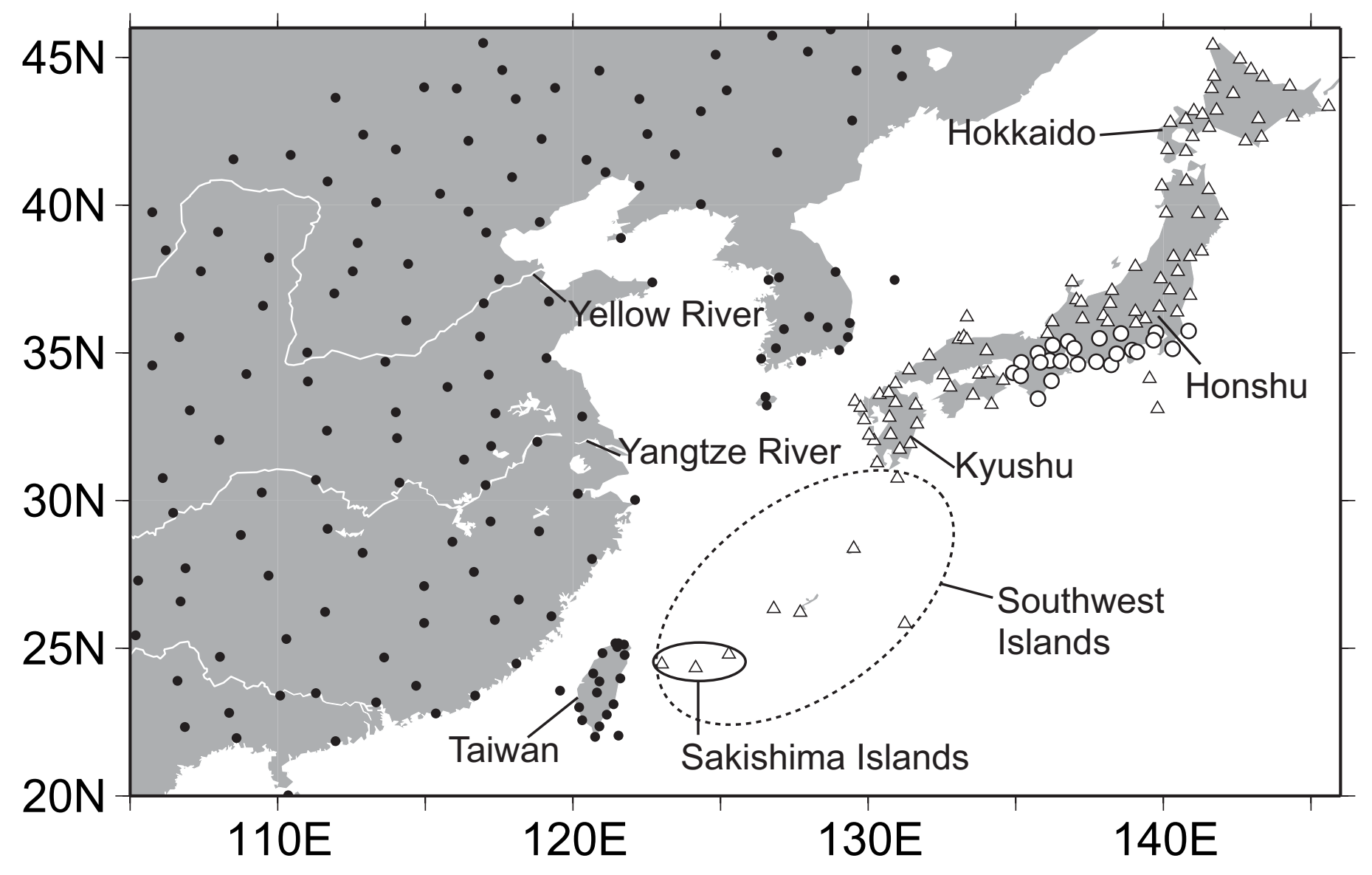

FIG. 1. Observational stations used in the present study. Open circles: the 24 stations on the Pacific Ocean side of central Japan, where the interdecadal sunshine increase is very clear (see text in section 3). Triangles: other stations in Japan, from which sunshine and rainfall data were taken for the present study. Closed circles: stations in China, Taiwan and Korea, from which only rainfall data were taken. 

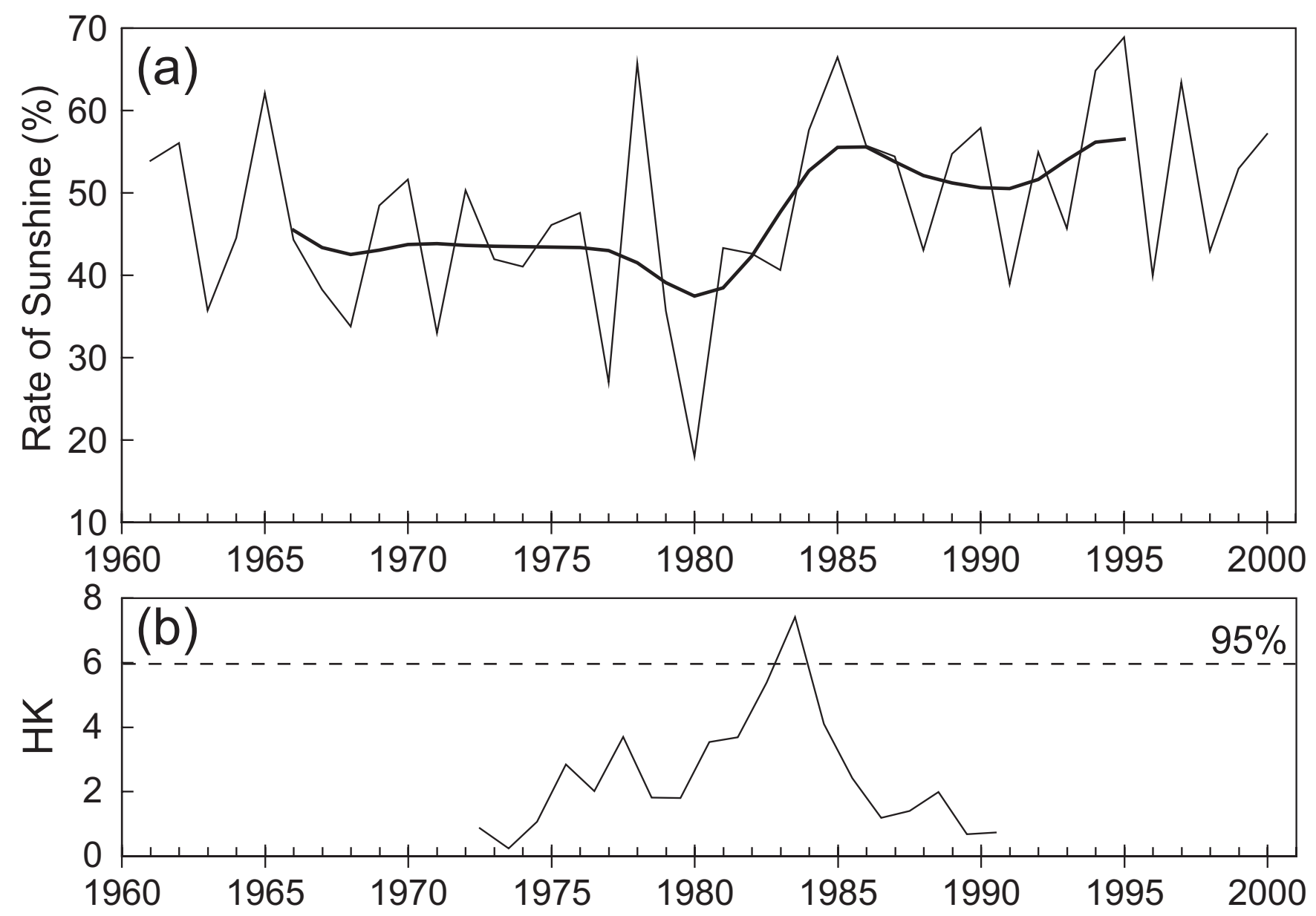

FIG. 2. (a) Interannual variation in the rates of sunshine, averaged over the 24 stations (open circles in Fig. 1), during 16-31 August (thin line) and its 7-year binomial running mean (thick line). (b) Time series of the Lepage statistic (HK), when the sampling numbers of the two groups are 12 (yr). The 95\% confidence level of this test is indicated by a broken line. 


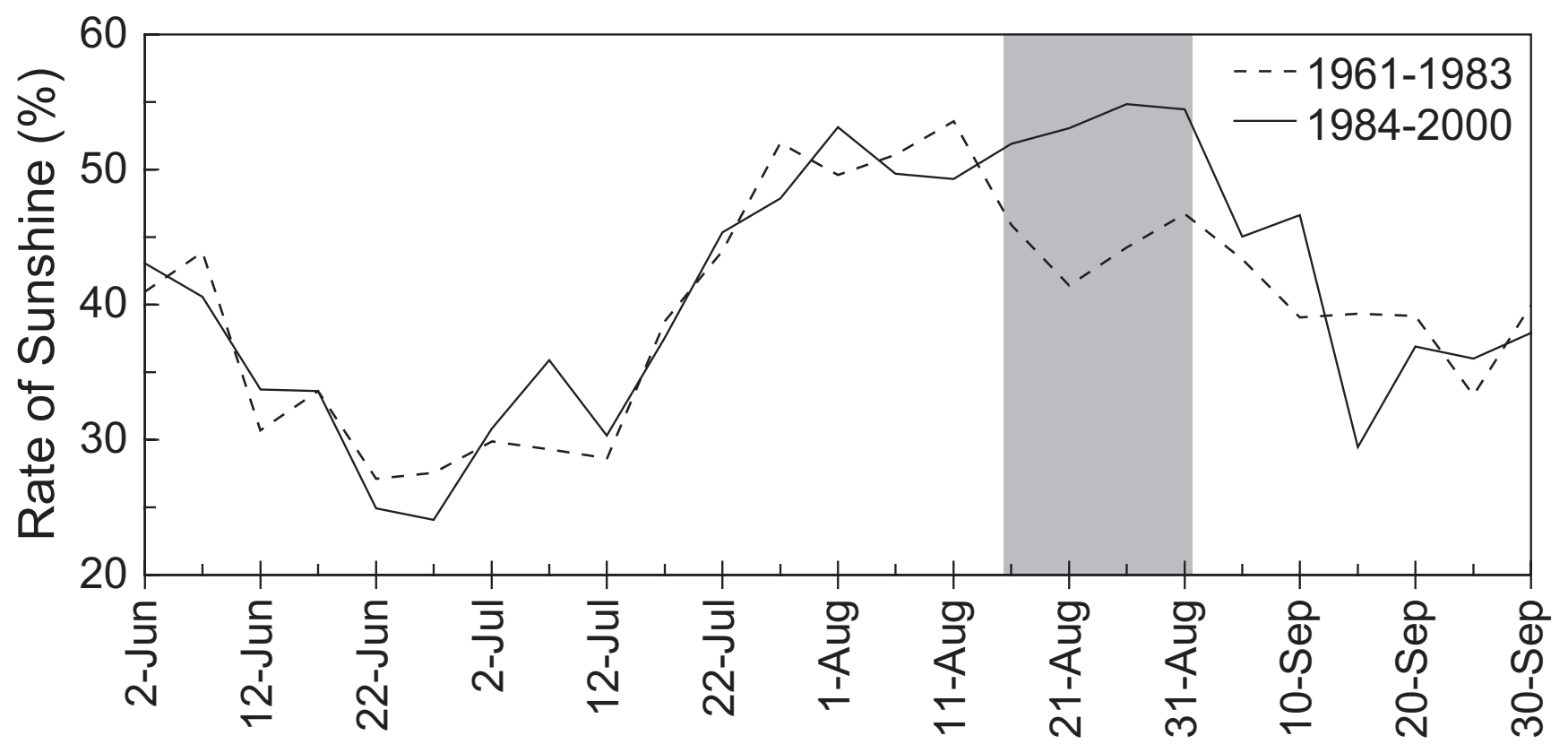

FIG. 3. Seasonal variations in the rates of sunshine (\%), averaged over the 24 stations in 1961-83 (broken line) and 1984-2001 (solid line). Daily values are compiled into pentad (5-day) mean ones, and the period of 16-31 August (LA) is shaded. 


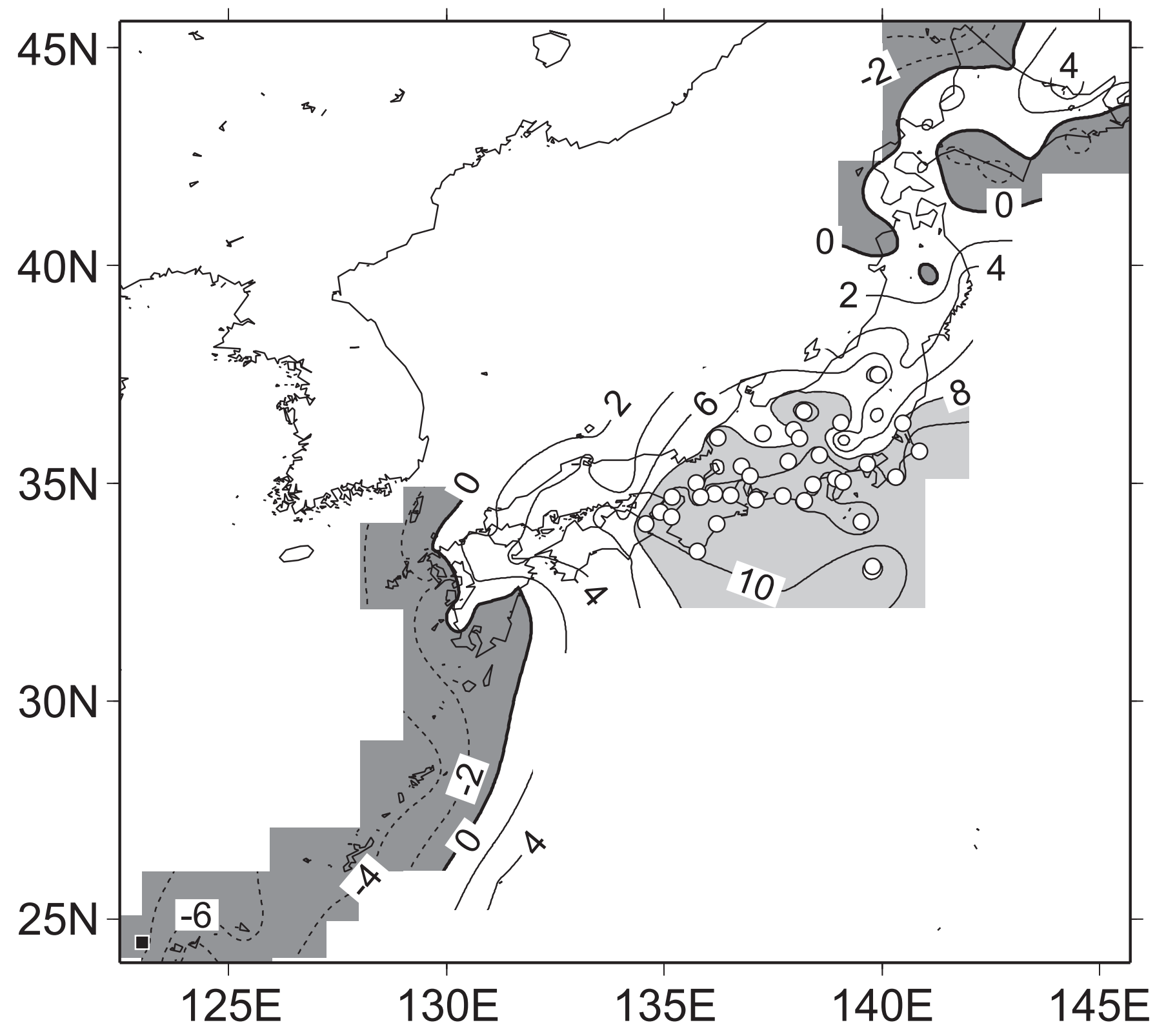

FIG. 4. Difference in the rates of sunshine (\%, 1984-2000 minus 1961-83) in Japan during 16-31 August (LA). Contour intervals are 2\%. Light shading indicates a region of more than $8 \%$ increase in the rates of sunshine, and heavy shading indicates a region of decrease in sunshine. Open circles indicate the stations (a closed square indicates the station) where the increase (decrease) is significant at a 95\% confidence level, according to the Student's t-test. 

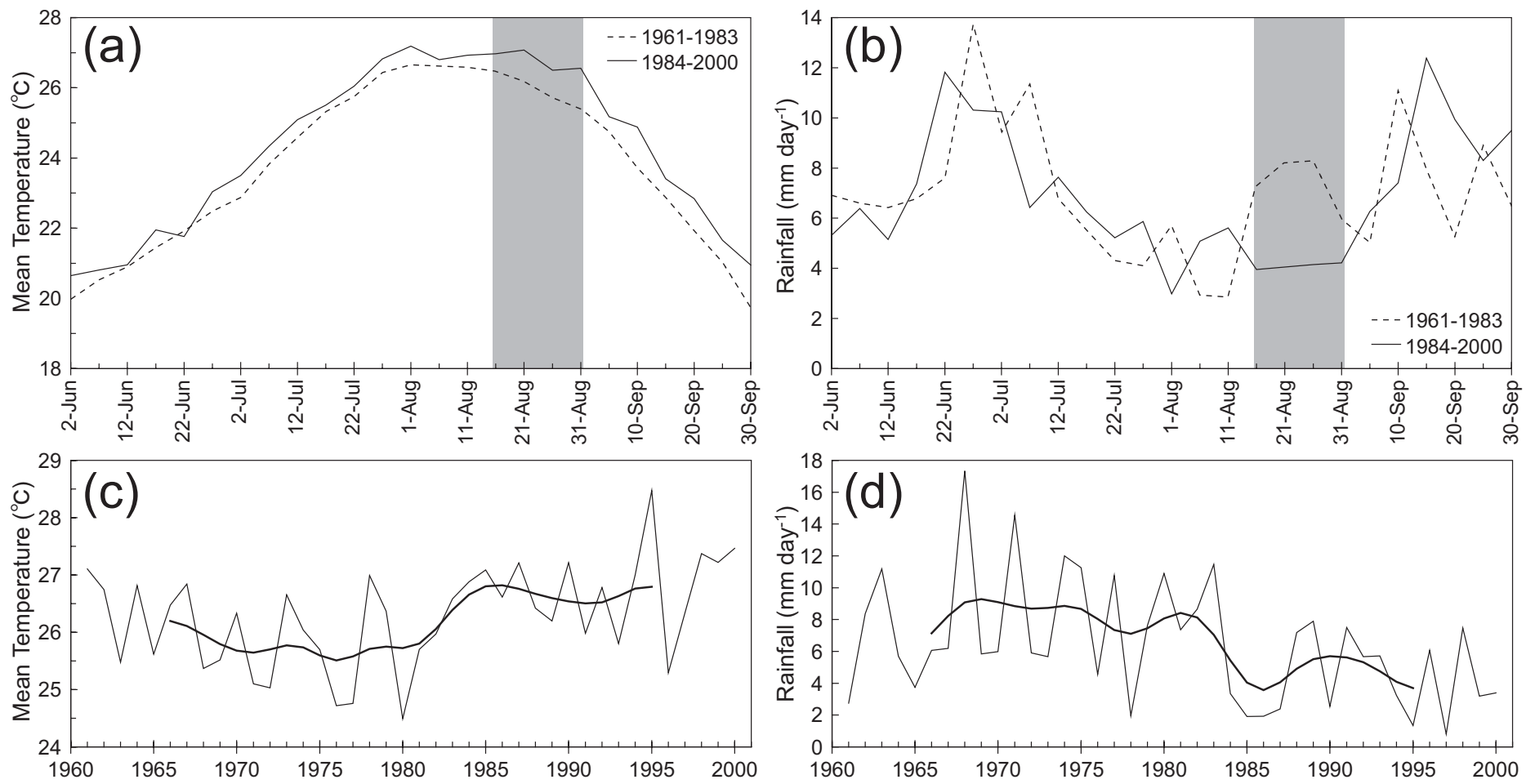

FIG. 5. (a) As in Fig. 3, except pentad-mean temperature $\left({ }^{\circ} \mathrm{C}\right)$. (b) As in Fig. 3, except rainfall $\left(\mathrm{mm} \mathrm{day}^{-1}\right)$. (c) As in Fig. 2a, except pentad-mean temperature $\left({ }^{\circ} \mathrm{C}\right)$. (d) As in Fig. 2a, except rainfall $\left(\mathrm{mm} \mathrm{day}^{-1}\right)$. 


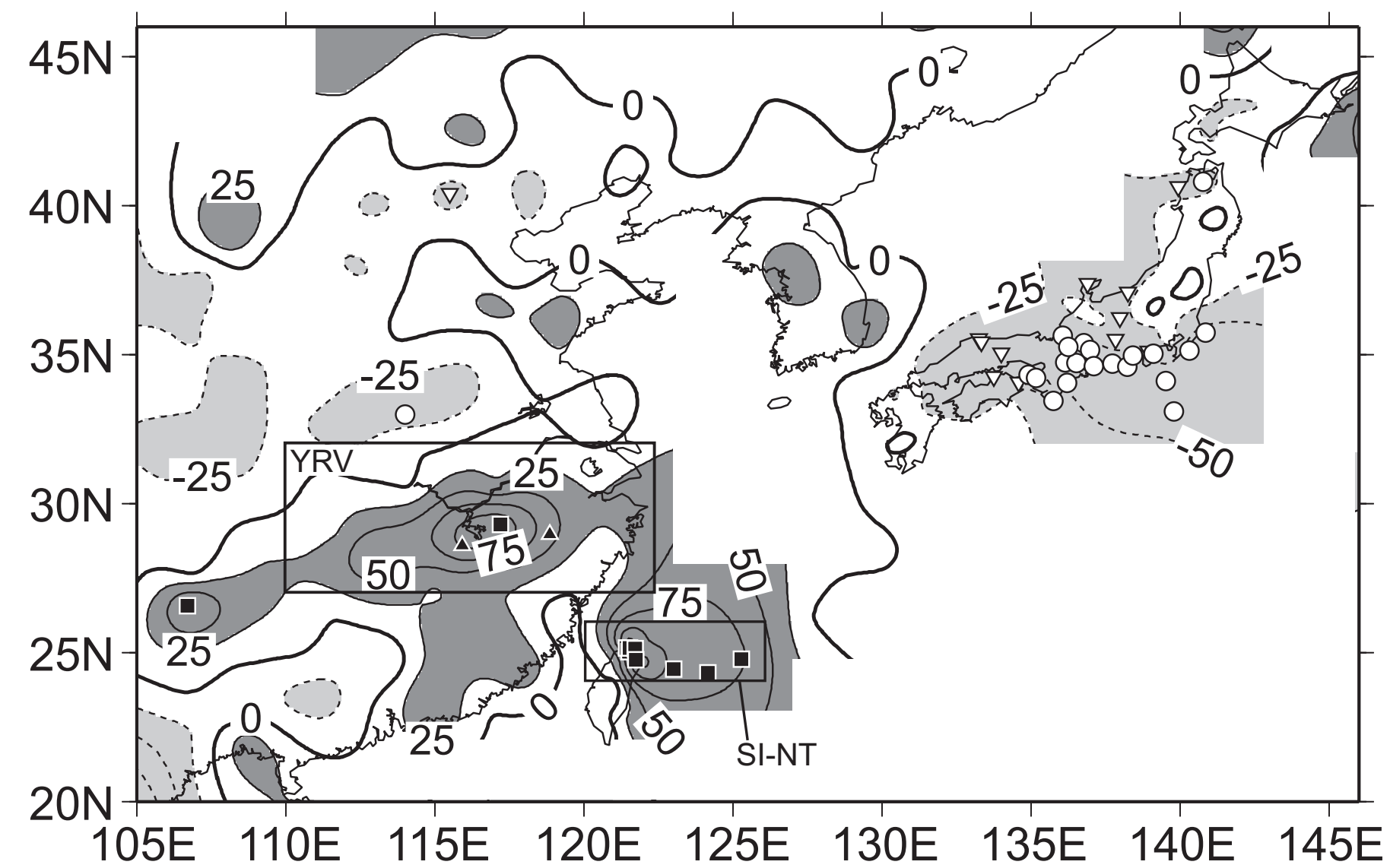

FIG. 6. Spatial pattern of the interdecadal change in rainfall $\left[100 \times\left(\mathrm{R}_{1984-2000}-\mathrm{R}_{1961-83}\right) / \mathrm{R}_{1961-83}(\%)\right.$, where $\mathrm{R}_{1961-83}\left(\mathrm{R}_{1984-2000}\right)$ is a rainfall amount during LA averaged in 1961-83 (1984-2000)] over East Asia. Contour intervals are $25 \%$. Heavy (light) shading indicates a region of more than $25 \%$ rainfall increase (decrease). Closed squares (open circles) are the stations where the increase (decrease) is significant at a 95\% confidence level, and closed triangles (inverse open triangles) are the stations where the increase (decrease) is significant at a 90-95\% level, according to the Student's t-test. Two boxes show regions where seasonal variations in rainfall are shown in Fig. 7. 
(a) SI-NT (24-26N, 120-126E)

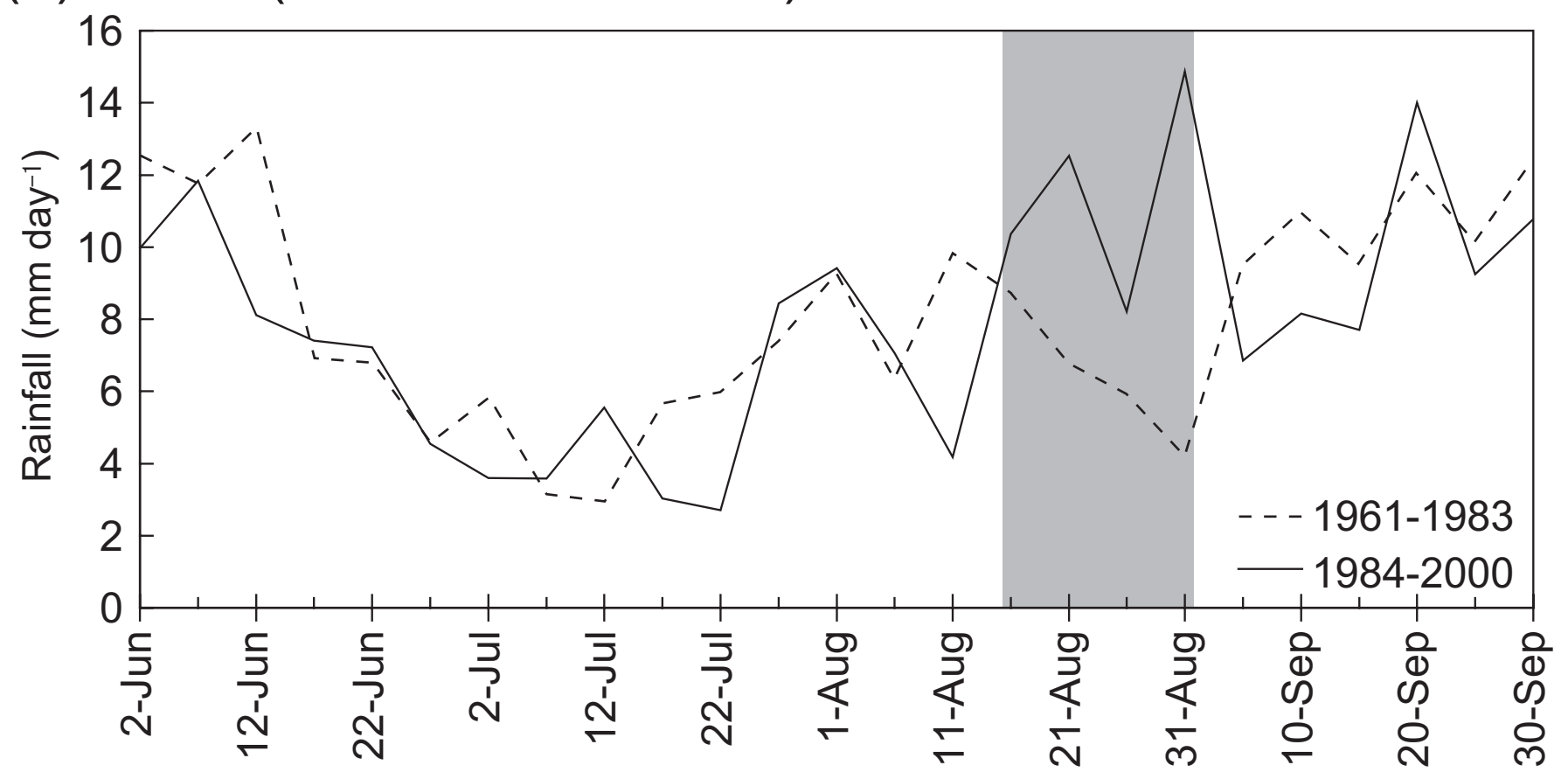

(b) YRV (27-32N, 110-122.5E)

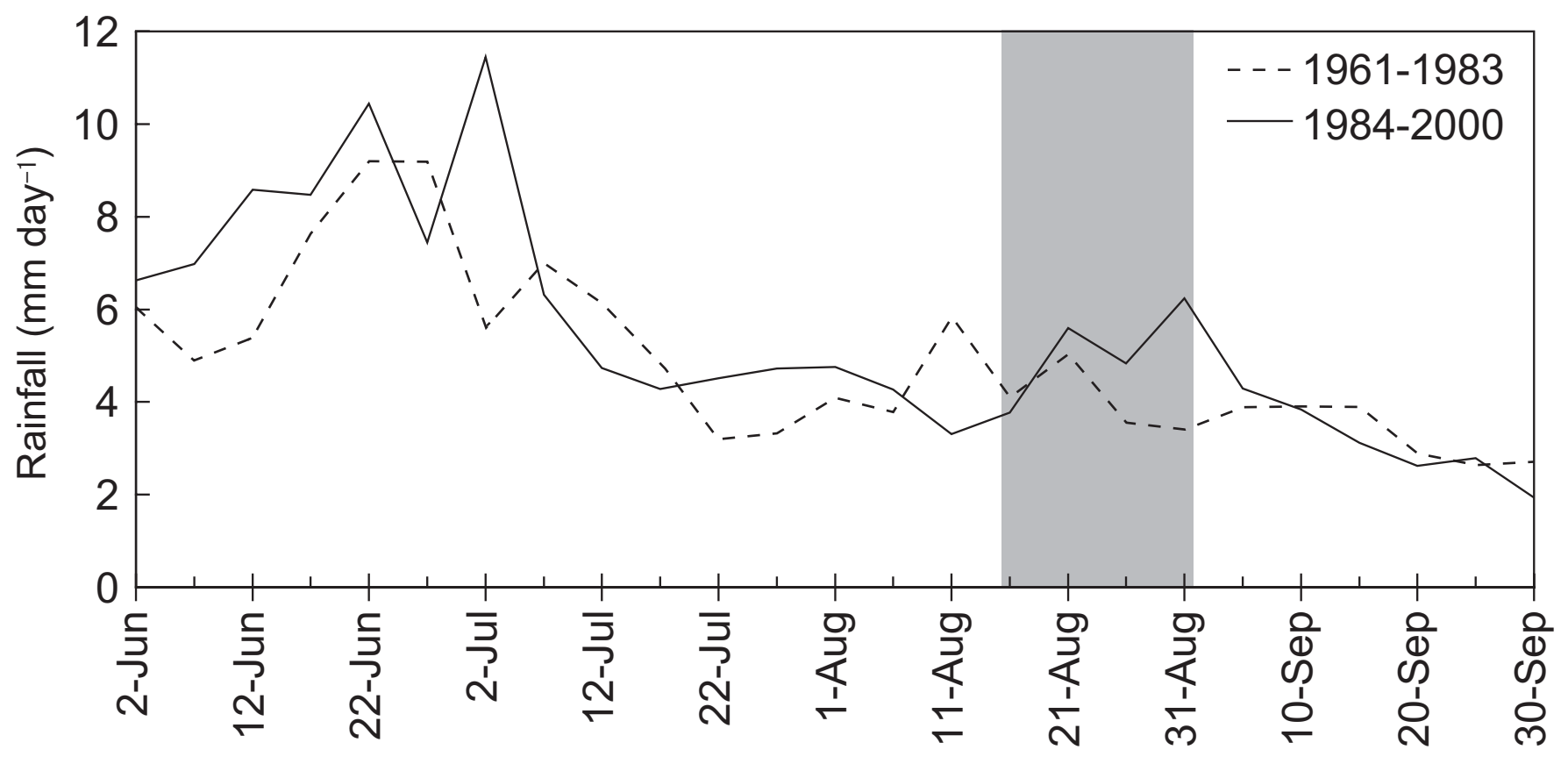

FIG. 7. (a) As in Fig. $5 b$, except in the SI-NT region $\left(24^{\circ}-26^{\circ} \mathrm{N}\right.$, $\left.120^{\circ}-126^{\circ} \mathrm{E}\right)$ and $(\mathrm{b})$ in the $\mathrm{YRV}$ region $\left(27^{\circ}-32^{\circ} \mathrm{N}, 110^{\circ}-122.5^{\circ} \mathrm{E}\right)$. 


\section{(a) 1961-1983}

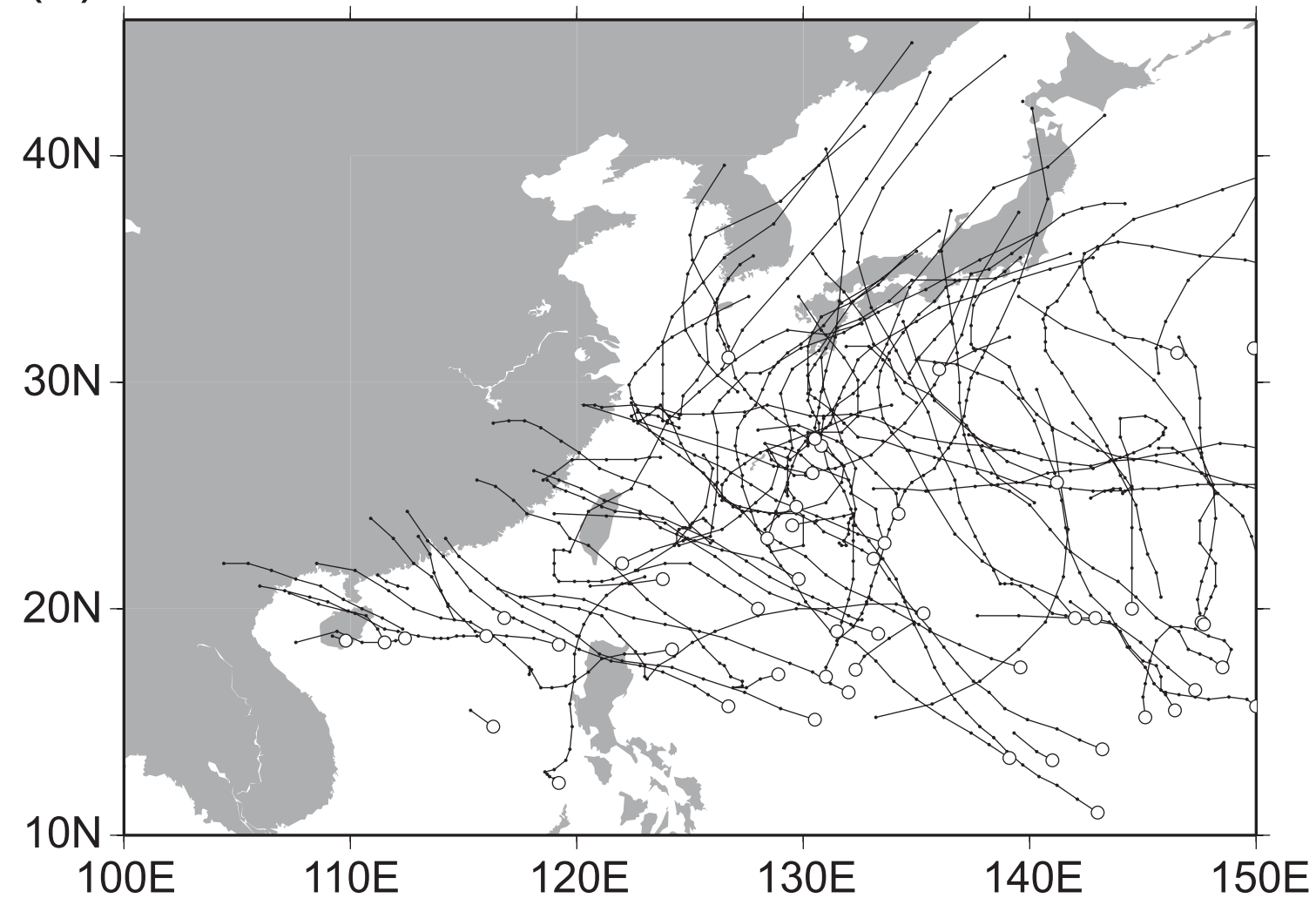

\section{(b) $1984-2000$}

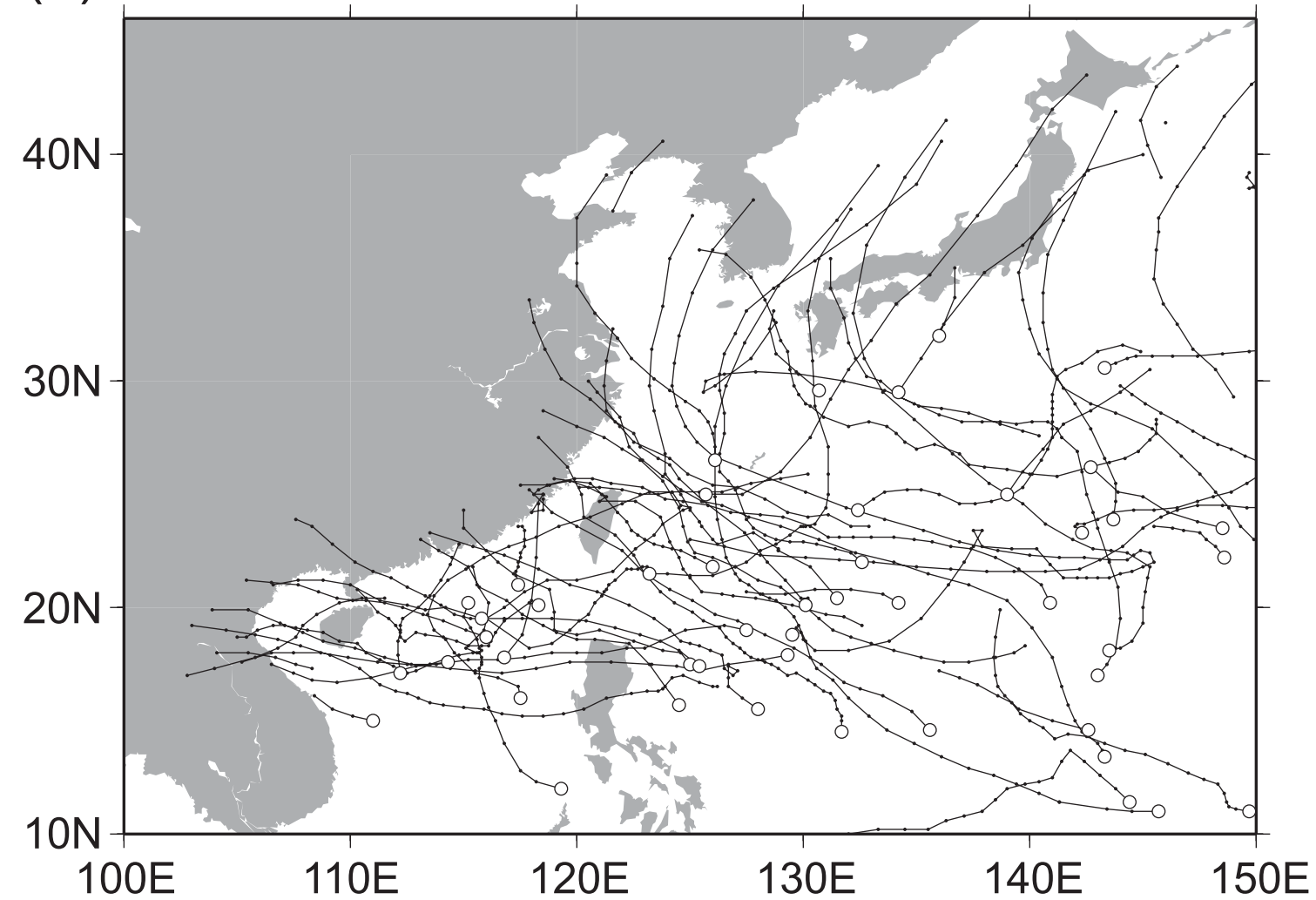

FIG. 8. Genesis locations (open circles) and tracks (dots with lines) of all typhoons that existed during 16-31 August (LA) over the WNP region in (a) 1961-83 and (b) 1984-2000, and (c) the difference in the typhoon passage frequency (\%) within each $5^{\circ} \times 5^{\circ}$ grid box (1984-2000 minus 1961-83) during LA. For (c), contour intervals are $1 \%$, and heavy (light) shading indicates a significant increase (decrease) at a $95 \%$ confidence level, estimated from the Monte Carlo simulations (10,000 resampling trials). Two boxes are regions where seasonal variations in typhoon passage frequency are shown in Fig. 9. 
(c) $1984-2000$ minus $1961-1983$

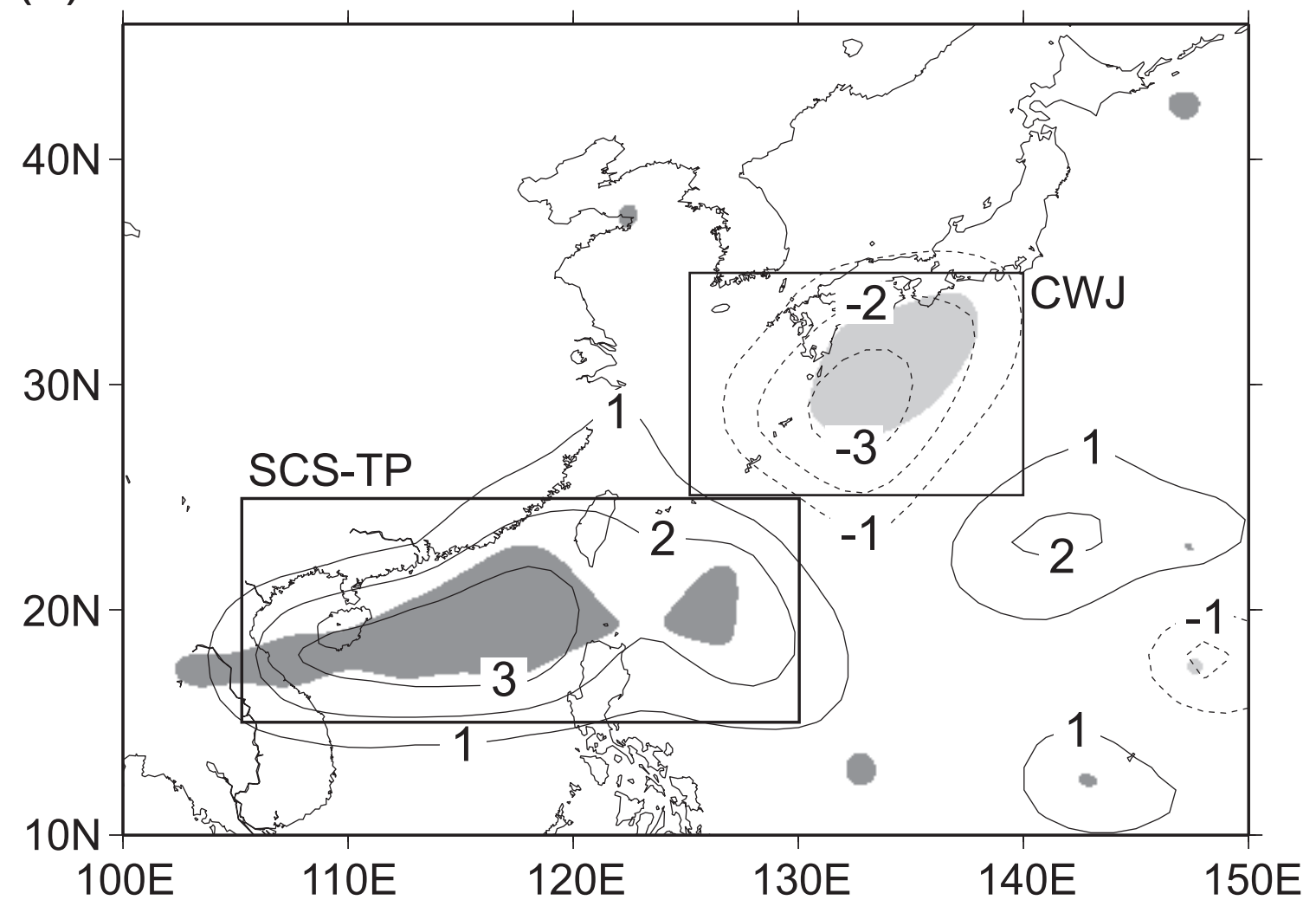

FIG. 8 (Continued). 
(a) CWJ (25-35N, 125-140E)

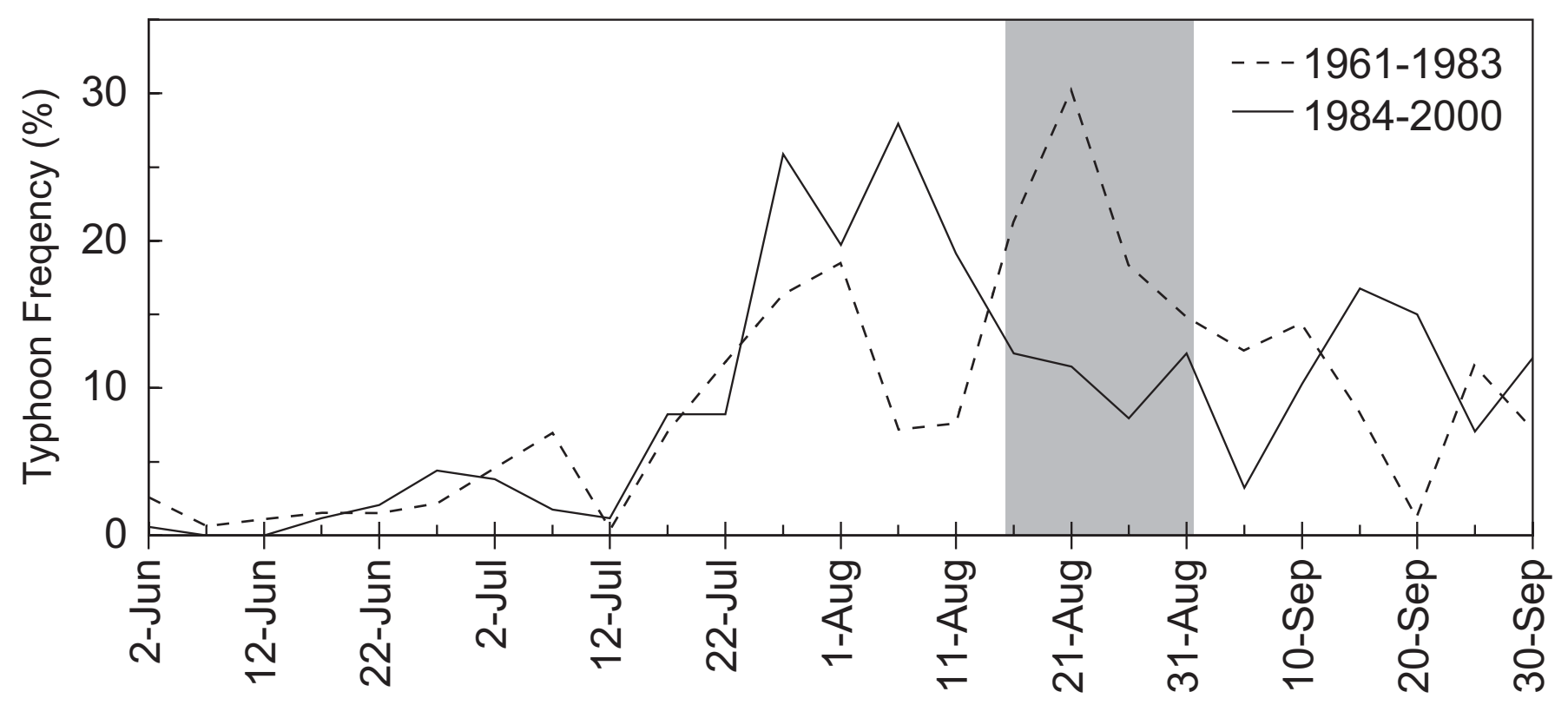

(b) SCS-TP $(15-25 \mathrm{~N}, 105-130 \mathrm{E})$

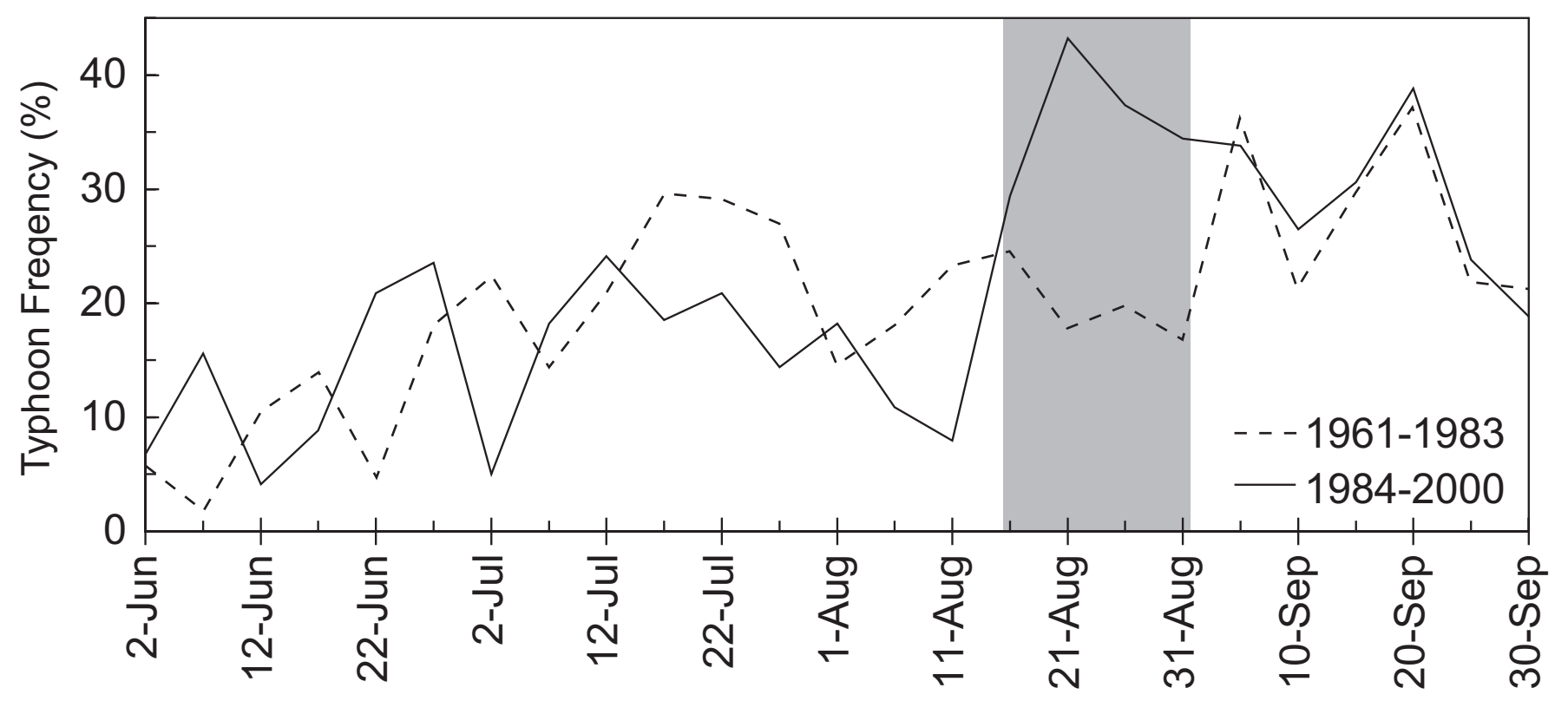

FIG. 9. As in Fig. 3, except the typhoon passage frequency (\%) over the (a) CWJ and (b) SCS-TP areas. 


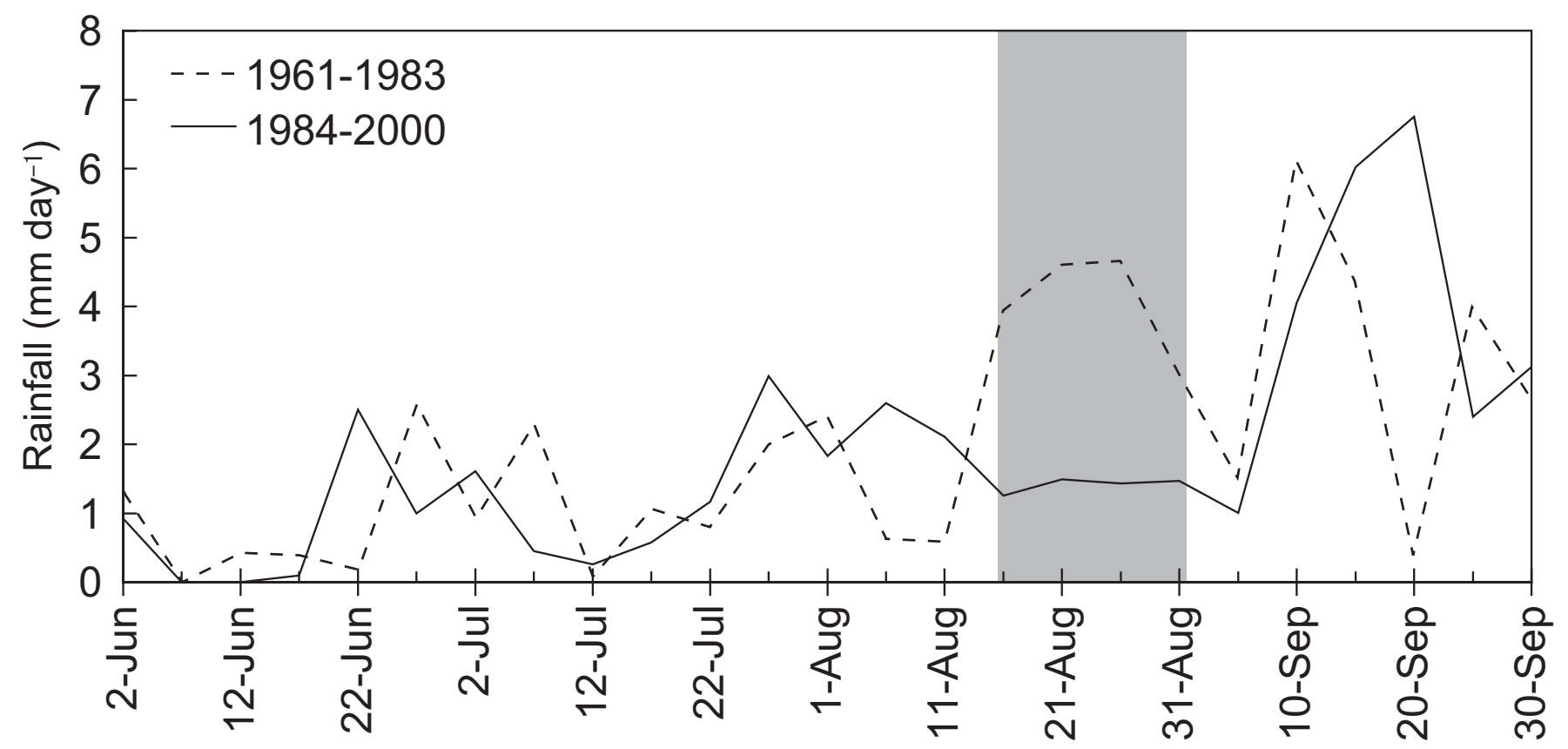

FIG. 10. As in Fig. 3, except the accumulated rainfall $\left(\mathrm{mm} \mathrm{day}^{-1}\right)$ when typhoons existed within the CWJ area. 


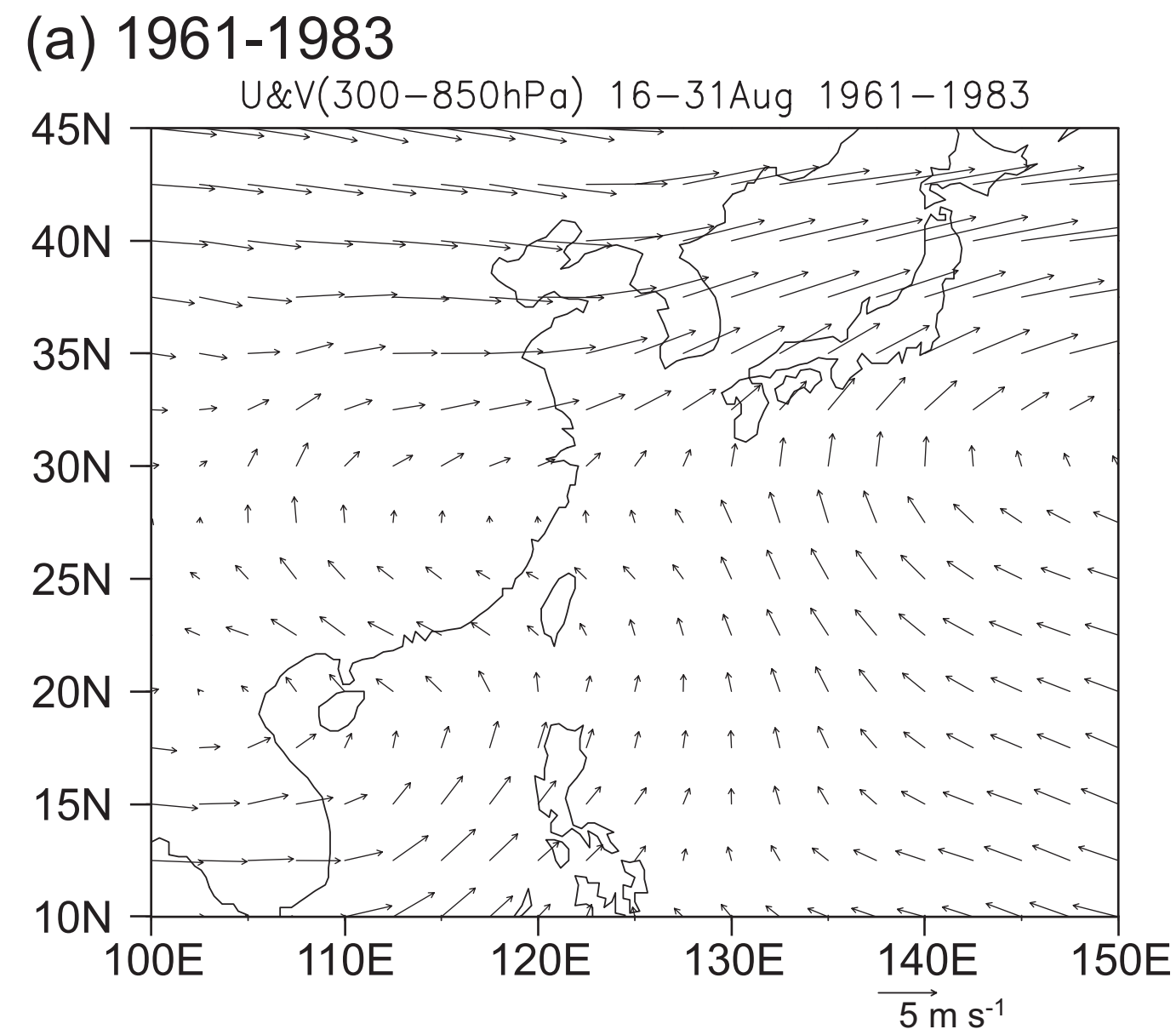

(b) $1984-2000$

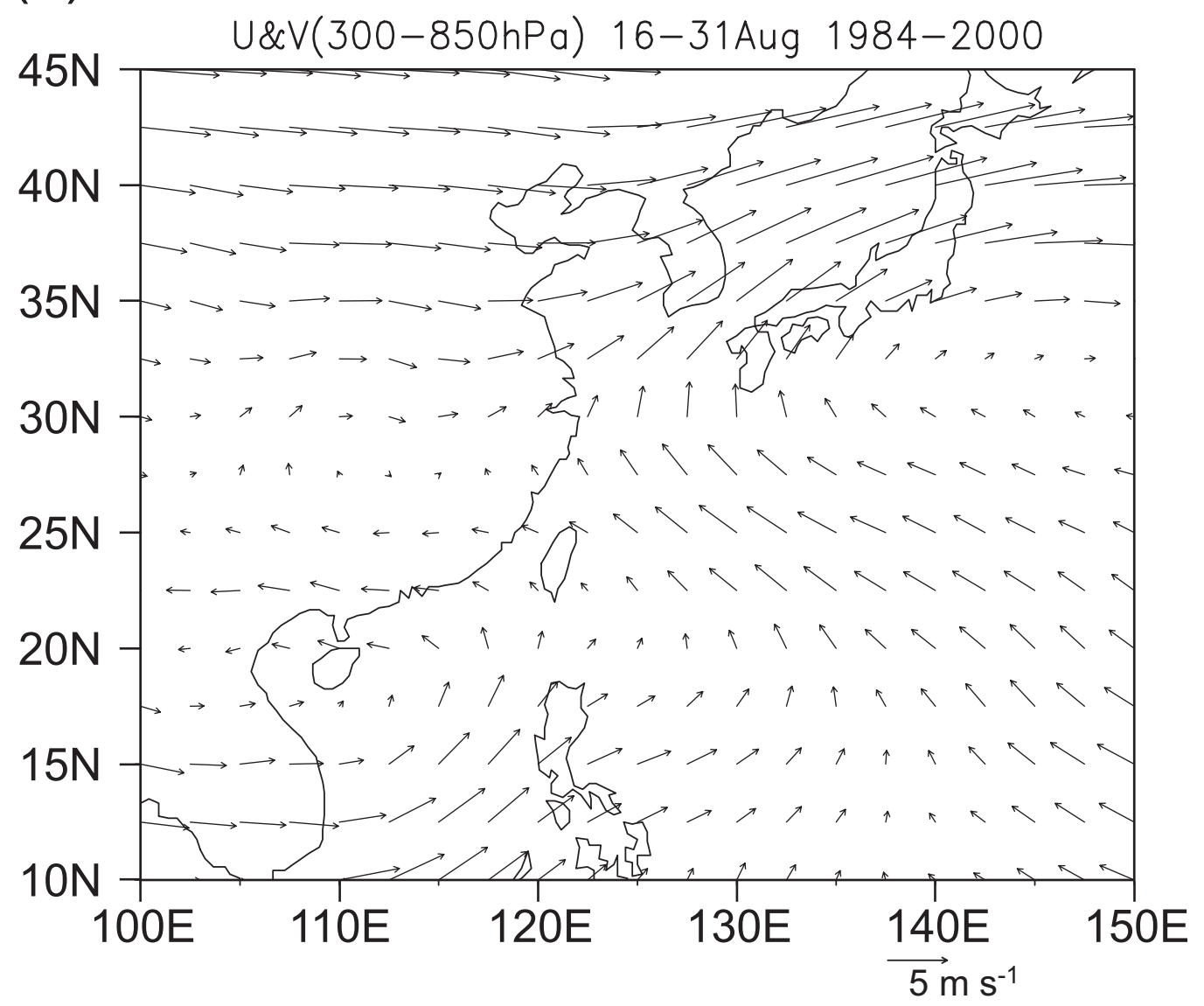

FIG. 11. Pressure-weighted (300-850 hPa) horizontal wind circulation during the period of 16-31 August (LA) in (a) 1961-83 and (b) 1984-2000. 
(a) $1961-1983$

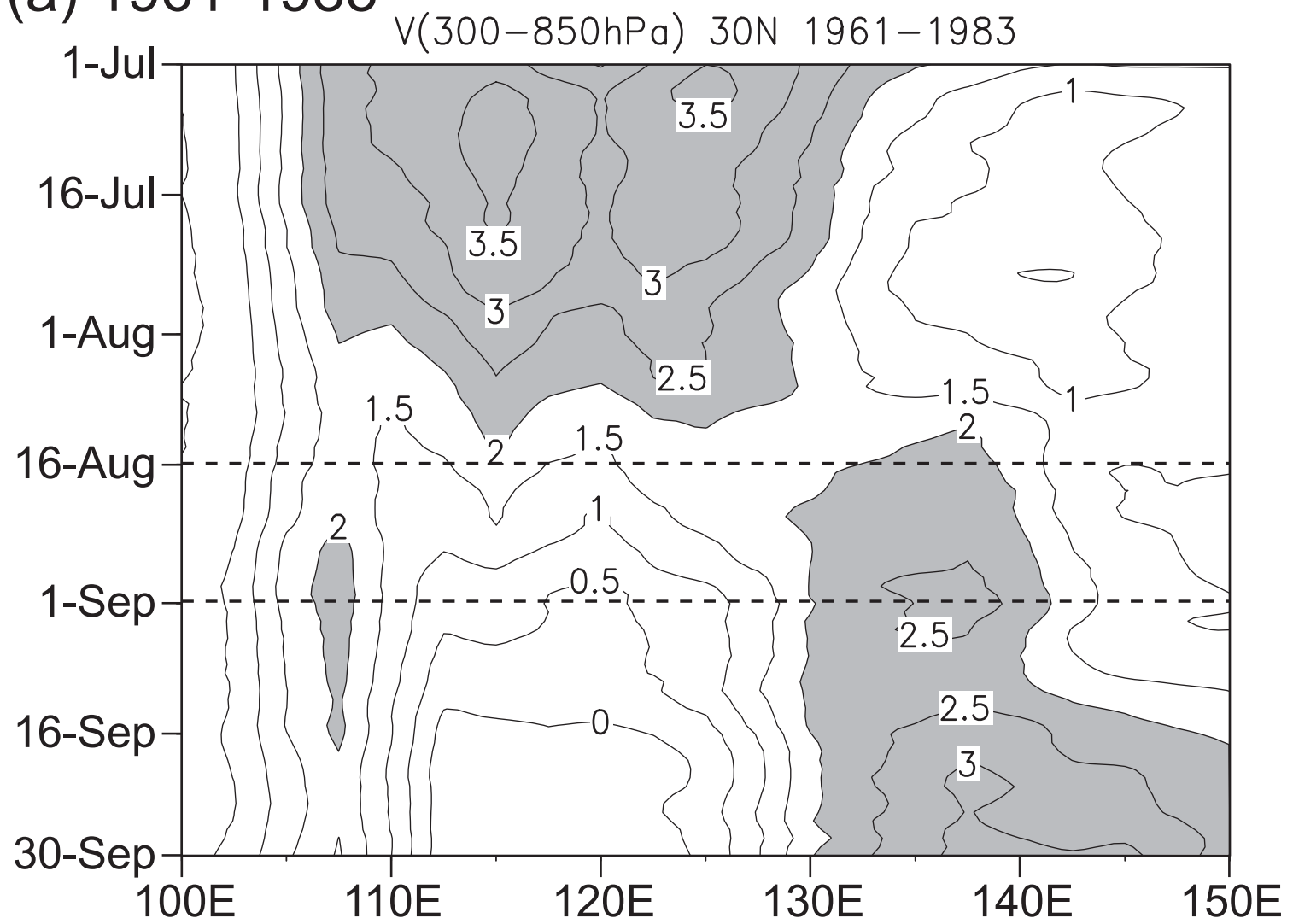

(b) $1984-2000$

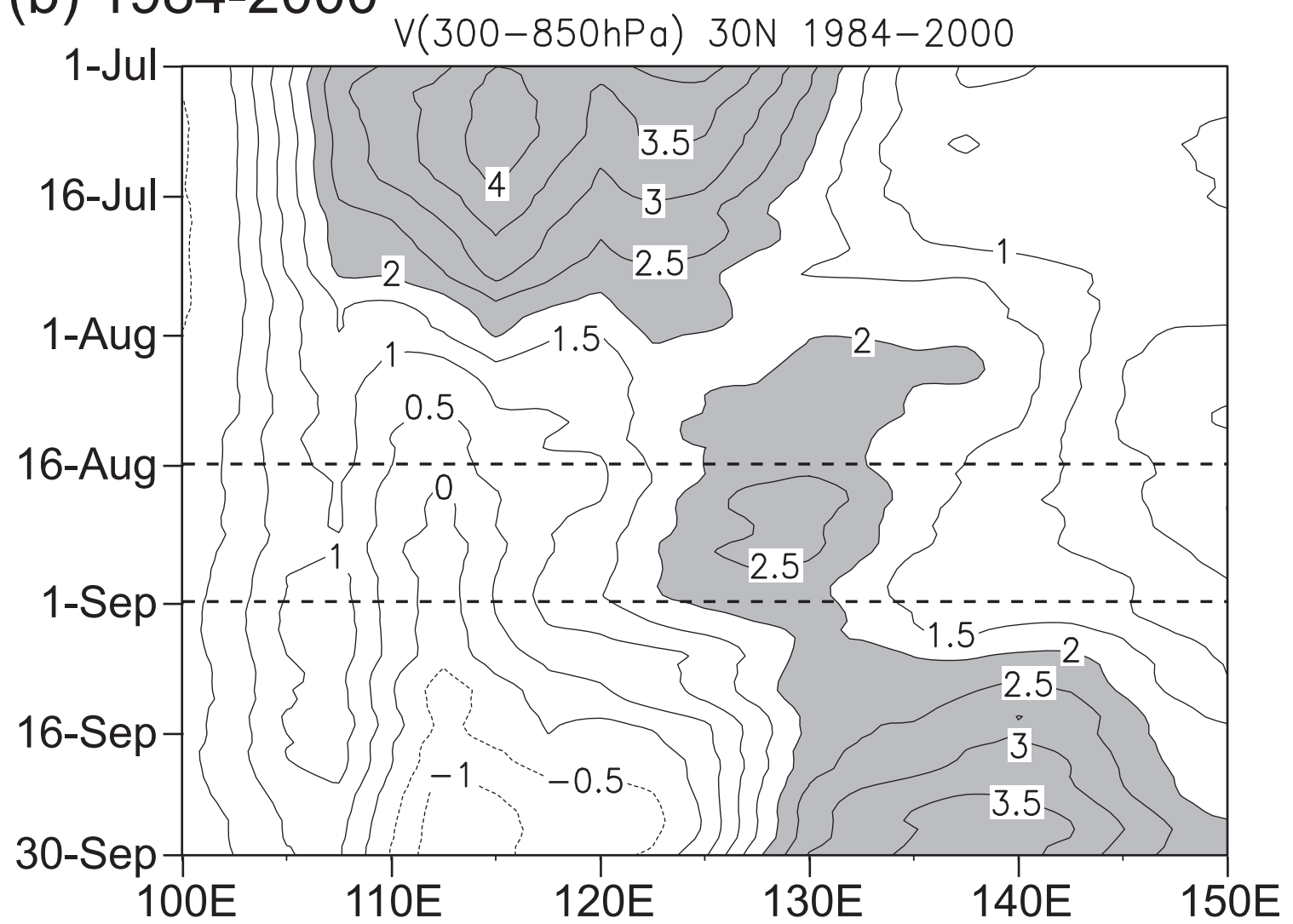

FIG. 12. Time-longitude sections of the meridional wind component of the pressure-weighted $\left(300-850 \mathrm{hPa}\right.$ ) flow along $30^{\circ} \mathrm{N}$ from July to September in (a) 1961-83 and (b) 1984-2000 (smoothed by a 25-day unweighted running mean). Contour intervals are $0.5 \mathrm{~m} \mathrm{~s}^{-1}$, and areas where the southerly wind component is stronger than $2 \mathrm{~m} \mathrm{~s}^{-1}$ are shaded. Dashed lines indicate the beginning and the end of LA. 